\title{
Avaliação da concentração de metais pesados em áreas olerícolas no Estado de Minas Gerais ${ }^{1}$
}

\author{
Raphael B. A. Fernandes², Walcrislei V. Luz ${ }^{2}$, Maurício P. F. Fontes ${ }^{2} \&$ Luiz E. F. Fontes ${ }^{2}$
}

\begin{abstract}
RESUMO
O presente trabalho teve como objetivo avaliar a presença dos metais pesados $\mathrm{Cd}, \mathrm{Pb}, \mathrm{Cu}, \mathrm{Cr}$, Fe, $\mathrm{Mn}, \mathrm{Mo}, \mathrm{Ni}$ e $\mathrm{Zn}$, em solos agrícolas, água de irrigação e alguns vegetais, provenientes de áreas olerícolas do estado de Minas Gerais. As amostras foram submetidas a digestão ácida e os teores de metais pesados determinados em um espectrofotômetro de emissão de plasma. A maior parte das amostras de solo apresentou baixos teores totais de metais pesados não indicando acumulação desses elementos, à exceção de $\mathrm{Cr}$ e $\mathrm{Cd}$, que exibiram teores totais os quais justificam análises complementares; entretanto, para esses elementos, os dados de extração com DTPA foram próximos de zero indicando sua baixa disponibilidade. Nas amostras de água apenas os elementos $\mathrm{Cd}$ e Pb não foram identificados. Considerando-se os teores máximos legais permitidos, poucas foram as amostras que superaram os limites. Nas amostras de olerícolas, os teores de $\mathrm{Cd}, \mathrm{Cr}$ e $\mathrm{Ni}$ nem se aproximaram do limite crítico e os teores dos demais elementos ultrapassaram levemente, em sua ampla maioria, o limite considerado. De maneira geral, os dados indicaram que as amostras de solo, água e olerícolas analisadas não estão contaminadas por metais pesados.
\end{abstract}

Palavras-chave: contaminação ambiental, elementos traços, poluição

\section{Evaluation of heavy metal concentrations in vegetable crop cultivation areas in Minas Gerais, Brazil}

\begin{abstract}
The objective of this study was to investigate the presence of heavy metals ( $\mathrm{Cd}, \mathrm{Pb}, \mathrm{Cu}, \mathrm{Cr}, \mathrm{Fe}, \mathrm{Mn}, \mathrm{Mo}, \mathrm{Ni}$ and $\mathrm{Zn})$ in agricultural soils, irrigation waters and some vegetable crops in the State of Minas Gerais, Brazil. Samples were submitted to an acid digestion and the heavy metal contents were determined using an ICP-OES. The majority of soil samples presented low heavy metal content, and did not indicate accumulation of these elements in soil, with the exception of $\mathrm{Cr}$ and $\mathrm{Cd}$, which presented contents justifying complementary analysis. However, for these elements, the DTPA extraction data were close to zero, indicating their low availability. In water samples the presence of $\mathrm{Cd}$ and $\mathrm{Pb}$ was not detected. Considering the maximum contents permitted by the Brazilian legislation, only a few samples were above the limits. In the vegetables samples, contents of $\mathrm{Cd}, \mathrm{Cr}$ and $\mathrm{Ni}$ not even approached the critical limit, and the majority of the other elements barely exceeded the considered limit. In general, the data show that the soil, water and vegetables samples analyzed were not contaminated by heavy metals.
\end{abstract}

Key words: environmental contamination, trace elements, pollution

1 Trabalho realizado com recursos da FAPEMIG (CAG 1947/95) e PRODOC/CAPES, apresentado no 4th International Symposium Environmental Geochemistry in Tropical Countries, Búzios, RJ, 2004

2 DPS/UFV, Av. P.H. Rolfs, s/n, 36570-000, Viçosa, MG. Fone: (31) 3899-1071. E-mail: raphael@ufv.br; walcrisleieab@yahoo.com.br; mpfontes@ufv.br; luizfontes@ufv.br 


\section{INTRODUÇÃO}

A preservação do meio ambiente e a melhoria da qualidade de vida, constituem uma preocupação cada dia mais evidente da sociedade; neste contexto e como produto de diferentes atividades antrópicas, a discussão acerca da acumulação de metais pesados em alimentos, no solo e na água de consumo humano, tem sido uma constante.

Os metais pesados estão naturalmente presentes na constituição de solos e rochas mas têm se apresentado cada vez mais próximos da cadeia alimentar dos animais e, em especial, da do homem. No tocante ao solo agrícola, recurso natural que suporta a produção de alimentos além de componente importante do ciclo hidrológico, a elevação dos teores de metais pesados vem sendo associada à aplicação de corretivos e adubos agrícolas, utilização de água de irrigação contaminada ou de produtos como lodo de esgoto, compostos de lixo urbano e resíduos diversos de indústria ou mineração. Uma vez nos solos agrícolas, esses elementos podem, ainda, sob determinadas circunstâncias, ser absorvidos pelas plantas, que fazem parte da alimentação humana ou animal.

A legislação brasileira, seja a ambiental ou mesmo a referente aos aspectos sanitários alimentares, ainda é pouco contundente com relação aos limites aceitáveis ou permitidos de metais pesados em solos, águas e alimentos. Existe uma carência muito grande de dados nacionais que subsidiem os legisladores e órgãos ambientais sendo, muitas vezes, utilizado valores limites verificados e utilizados em outros países.

Poucos são os trabalhos na literatura nacional que se propõem fazer um levantamento mais amplo da acumulação de metais pesados em mais de um compartimento ambiental, como os efetuados por Ramalho et al. (2000) e Duarte \& Pasqual (2000). Alguns trabalhos restringem seus objetivos a determinado compartimento: solo (Fadigas et al., 2002; Campos et al., 2003; Marques, 2004) e água (Rietzler et al., 2001; Costa et al.,2005), ou ainda, se dedicam ao comportamento do solo a partir da aplicação de resíduos (Costa et al., 1997, 2001; Mantovani et al., 2003; Teixeira et al. 2005). Especificamente com relação ao compartimento hídrico, merece destaque o programa de monitoramento da qualidade das águas efetuado pela CETESB para o Estado de São Paulo, que inclui, dentre as variáveis analisadas, a presença de metais pesados, com relatórios disponibilizados na internet (CETESB, 2006).

Desta forma, se objetivou neste trabalho avaliar os teores totais de metais pesados em amostras de olerícolas, solos e água, e os teores disponíveis em amostras de solos provenientes de áreas com intensa atividade olerícola no estado de Minas Gerais,

\section{MATERIAL E MÉTODOS}

\section{Pontos de amostragem}

Inicialmente foram identificados municípios mineiros com produção significativa de cada uma das olerícolas escolhidas: alface (Mário Campos, Viçosa e Juiz de Fora); batata
(Bom Repouso, Borda da Mata e Araxá); beterraba (Lagoa Dourada e São João del Rei); cenoura (São Gotardo, Lagoa Dourada e Carandaí); repolho (Carandaí e Barbacena) e tomate (Carandaí, Barbacena e Coimbra). As coletas ocorreram entre abril e maio de 2003; sendo visitadas propriedades com olerícolas em ponto de colheita.

Obtiveram-se, no momento da coleta das amostras, informações acerca do tempo de cultivo da gleba amostrada, da adubação utilizada mais recentemente e da origem da água utilizada para irrigação. Com a utilização de um equipamento do tipo GPS foram tomadas as coordenadas geográficas do ponto de amostragem de solo, que foi coletado sempre lateralmente ao local de coleta da olerícola em análise.

\section{Coleta das amostras}

Em cada município foram visitados cinco diferentes produtores das olerícolas, onde se coletaram amostras de solo e de olerícolas e, quando possível, também da água utilizada para irrigação; no total, foram coletadas 80 amostras de solo e de vegetais e 65 amostras de água de irrigação.

As amostras de solo foram coletadas com um trado de inox, introduzido até $20 \mathrm{~cm}$ de profundidade. A partir de determinado número de amostras simples, variável em função do tamanho da área e nunca inferior a 10 tomadas, o material foi homogeneizado e uma porção de aproximadamente $500 \mathrm{~g}$ foi transferida para sacos plásticos.

$\mathrm{Na}$ amostragem das olerícolas coletaram-se as partes comestíveis de alface (folhas), batata (tubérculos), beterraba (raiz), cenoura (raiz), repolho (folhas) e tomate (frutos), todos em ponto de colheita, após a qual as amostras foram imediatamente acondicionadas em sacos plásticos e mantidas sob refrigeração. No caso da alface e repolho uma única amostra foi retirada por gleba e, para as demais olerícolas, no mínimo cinco unidades de frutos, tubérculos ou raízes foram coletadas.

Amostras de água foram coletadas, quando possível, no ponto de captação do sistema de irrigação da propriedade com a utilização de frascos de polietileno. As amostras foram imediatamente acidificadas com ácido nítrico diluído, levando-se a pH inferior a 4. Uma vez lacrados, os frascos foram mantidos sob refrigeração.

No dia 26/03/2003, se visitou a Central de Abastecimento de Minas Gerais S/A (CEASA-MG), localizada em Belo Horizonte, onde foram recolhidas 114 amostras das mesmas olerícolas coletadas a campo, provenientes de 32 diferentes municípios mineiros. Após a coleta, as amostras foram imediatamente submetidas a refrigeração. A sede dos municípios em que foram efetuadas as coletas de campo e os de origem dos produtos coletados no CEASA-MG, é apresentada na Figura 1.

\section{Preparação das amostras}

Uma vez no laboratório, as amostras de solo foram secadas à sombra e, posteriormente, submetidas a tamisagem em peneira de $2 \mathrm{~mm}$, de forma a se obter a terra fina seca ao ar (TFSA). Subamostras foram submetidas à caracterização física (composição textural, segundo Ruiz, 2004) e química de rotina (EMBRAPA, 1997; Deffelipo \& Ribeiro, 1996). 


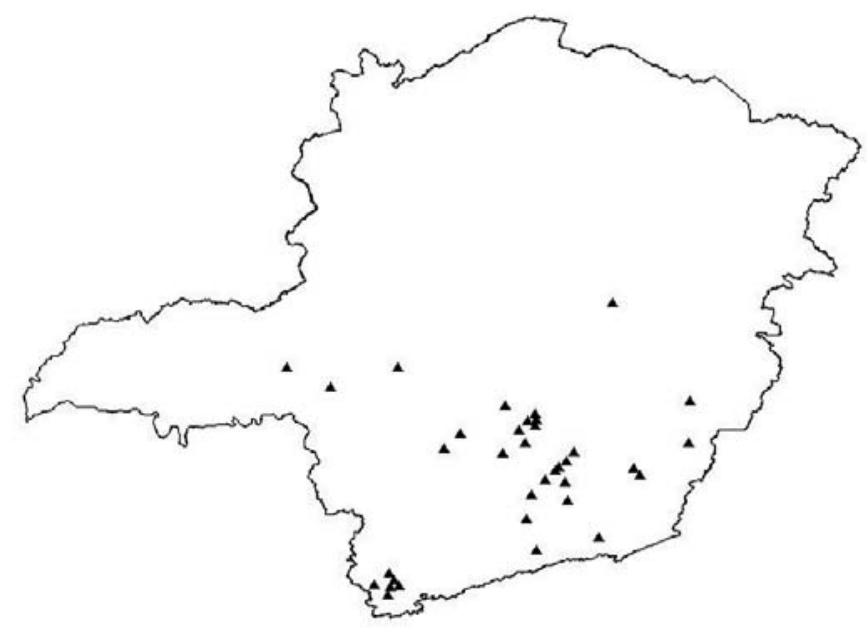

Figura 1. Localização da sede dos municípios visitados para a coleta de amostras na expedição de campo e os de origem dos produtos coletados no CEASA-MG

Uma vez no laboratório, as olerícolas foram lavadas sob água corrente destilada e deionizada para a retirada de impurezas e transferidas para estufa para secagem a $60^{\circ} \mathrm{C}$. Uma vez secas, as amostras foram moídas e o material guardado em sacos plásticos. As amostras de água foram acondicionadas em geladeira até posterior análise.

Digestão das amostras e análises de solos, vegetais e águas

Subamostras dos solos, em triplicata, foram submetidas ao ataque ácido para a completa dissolução dos componentes minerais. A digestão ácida foi efetuada em cadinhos de teflon dispostos em banho de areia sobre chapa quente, com a adição de $\mathrm{HF}, \mathrm{HNO}_{3}, \mathrm{H}_{2} \mathrm{SO}_{4}$ e $\mathrm{HClO}_{4}$ concentrados (Baker \& Amacher, 1982). Cada cadinho recebeu de 0,2300 a 0,2500 g de TFSA, previamente moída e passada em peneira de 100 mesh. Nas amostras de solo, também em triplicata, determinaram-se os teores de metais pesados, em suas formas consideradas disponíveis pelo extrator DTPA (Abreu et al., 2001), só que com base em peso. Ao final, calculou-se um índice de disponibilidade a partir da relação entre os teores disponíveis (DTPA) e os totais (digestão ácida).

Alíquotas de $20 \mathrm{~mL}$ das amostras de água foram submetidas a digestão ácida com $5 \mathrm{~mL}$ de mistura (3:1) nitroperclórica em erlemeyers, dispostos sobre chapa quente. Finalizada a digestão, o extrato foi guardado em geladeira, até posterior análise.

Amostras de aproximadamente $0,500 \mathrm{~g}$ do material vegetal foram digeridas até completa dissolução sobre chapa quente com adição de $10 \mathrm{~mL}$ de mistura (3:1) nitroperclórica. O extrato digerido foi guardado em geladeira, até posterior análise.

A determinação dos teores de metais pesados nos extratos das amostras de água, solo e vegetais e nos extratos de DTPA de solos, foi feita usando um espectrofotômetro de emissão ótica de plasma acoplado por indução (ICP-OES). Os metais pesados analisados foram: $\mathrm{Cd}, \mathrm{Pb}, \mathrm{Cu}, \mathrm{Cr}, \mathrm{Fe}, \mathrm{Mn}$, Mo, Ni e Zn. Os resultados obtidos, quando possível, foram contrastados com a legislação brasileira correspondente.

\section{RESULTADOS E DISCUSSÃO}

\section{Caracterização físico-química dos solos}

As classes texturais predominantes nos solos estudados foram a argila e a muito argilosa, que representaram 77,5\% das amostras avaliadas. Os solos argilosos são freqüentemente preferidos pelos agricultores, em especial por aqueles que desempenham atividades hortícolas. Esses solos apresentam maior potencial se comparados com os de textura média e arenosa, de reter contaminantes, entre eles os metais pesados, evitando que os mesmos sejam lixiviados e atinjam o lençol freático.

De forma geral, as amostras analisadas representam solos de boa qualidade química, o que é muito comum na atividade olerícola, tendo em vista as repetidas e volumosas adubações aplicadas. Os valores de $\mathrm{pH}$ denotam uma reação do solo favorável ao desenvolvimento vegetal e os teores de nutrientes se situam muito acima da média normalmente observada para solos mineiros. Considerando-se os valores médios obtidos (dados não apresentados) para as variáveis analisadas e de acordo com as classes de interpretação de fertilidade (Alvarez et al., 1999), o pH dos solos foi considerado "alto"; os teores de $\mathrm{P}$ e $\mathrm{K}$ disponíveis como "muito bons"; os teores de Ca e os valores de SB, CTC efetiva e V como "bons"; H+Al e CTC total como "médios"; teores de Mg como "baixos" e os teores de $\mathrm{Al}$ e os valores m como "muito baixos". Esses níveis de fertilidade justificam este trabalho de monitoramento, uma vez que a significativa adição de fertilizantes químicos e orgânicos no solo por olericultores, pode permitir a entrada de contaminantes, em especial de metais pesados.

\section{Teores totais de metais pesados nos solos}

Os teores totais dos metais pesados indicam a grande variabilidade de concentração desses elementos nos solos estudados (Tabela 1). Os teores de Cd variaram de 1,82 a 16,22 $\mathrm{mg} \mathrm{kg}^{-1}$ (média: 6,53 $\pm 3,1$ ); os de Cr de 13,47 a 411,65 $\mathrm{mg} \mathrm{kg}^{-1}$ (média: 111,71 $\pm 74,3$ ); os de $\mathrm{Cu}$ de 0 a 118,75 $\mathrm{mg} \mathrm{kg}^{-1}$ (média: 13,18 \pm 17,1); os de Fe de 19.709 a $929.143 \mathrm{mg} \mathrm{kg}^{-1}$ (média: $148.695 \pm 358.382$ ); os de Mn de 70 a $1.756 \mathrm{mg} \mathrm{kg}^{-1}$ (média: $367 \pm 291$ ); os de Ni de 4,10 a $85,27 \mathrm{mg} \mathrm{kg}^{-1}$ (média: $23,96 \pm 16,8$ ); os de $\mathrm{Pb}$ de 0 a $36,12 \mathrm{mg} \mathrm{kg}^{-1}$ (média: 5,23 \pm 7,8) e os de $\mathrm{Zn}$ de 8,33 a 275,41 $\mathrm{mg} \mathrm{kg}^{-1}$ (média: 41,88 \pm 34,5). O único elemento não verificado nas amostras de solo foi o molibdênio.

Como não existe, para o Estado de Minas Gerais, norma legal acerca de limites aceitáveis de metais pesados em solos utilizaram-se, para fins de comparação, os valores orientadores de referência de qualidade, prevenção e intervenção (Tabela 2), segundo a Companhia de Tecnologia de Saneamento Ambiental de São Paulo (CETESB, 2005).

O valor de referência de qualidade (VRQ) reflete a concentração natural média dos elementos, indicando situações de não contaminação. O valor de prevenção (VP) indica uma possível alteração prejudicial à qualidade dos solos, sendo utilizado em caráter preventivo e, quando excedido no solo, deverá ser exigido o monitoramento dos impactos decorrentes; já o valor de intervenção (VI) indica o limite 
Tabela 1. Teores totais de metais pesados presentes nas amostras de solo coletadas em cultivos olerícolas no Estado de Minas Gerais com o índice de disponibilidade entre parêntesis. Média de três repetições

\begin{tabular}{|c|c|c|c|c|c|c|c|c|c|c|}
\hline \multirow{2}{*}{$\mathbf{N}^{0}$} & \multirow{2}{*}{ Id } & Cd & $\mathrm{Cr}$ & $\mathrm{Cu}$ & $\mathrm{Fe}$ & $\mathrm{Mn}$ & Mo & $\mathrm{Ni}$ & $\mathrm{Pb}$ & $\mathrm{Zn}$ \\
\hline & & \multicolumn{9}{|c|}{$\mathrm{mg} \mathrm{kg}^{-1}$} \\
\hline 1 & $V \mid 1^{(1)}$ & $4,94\left(0^{(2)}\right)$ & $74,59(0)$ & $16,61(27)$ & $43.428(0)$ & $1.135(10)$ & $0^{(3)}(-)$ & $29,89(1)$ & $6,94(15)$ & $98,47(38)$ \\
\hline 2 & VI2 & $11,82(0)$ & $86,35(0)$ & $118,75(13)$ & $851.753(0)$ & $1756(7)$ & $0(-)$ & $37,20(1)$ & $20,15(5)$ & $125,44(24)$ \\
\hline 3 & VI3 & $7,78(0)$ & $65,59(0)$ & $9,76(39)$ & $63.191(0)$ & $276(10)$ & $0(-)$ & $27,13(1)$ & $0,00(-)$ & $64,81(35)$ \\
\hline 4 & VI4 & $7,60(0)$ & $113,57(0)$ & $56,43(18)$ & $66.542(0)$ & $641(12)$ & $0(-)$ & $62,58(1)$ & $6,71(31)$ & $97,66(30)$ \\
\hline 5 & VI5 & $7,37(0)$ & $124,22(0)$ & $37,18(16)$ & $59.040(0)$ & $606(15)$ & $0(-)$ & $58,70(1)$ & $9,32(25)$ & $80,92(26)$ \\
\hline 6 & MC1 & $4,28(0)$ & $136,48(0)$ & $19,94(16)$ & $39.178(0)$ & $527(14)$ & $0(-)$ & $35,00(1)$ & $0,00(-)$ & $37,14(21)$ \\
\hline 7 & MC2 & $6,14(0)$ & $207,79(0)$ & $26,51(20)$ & $58.458(0)$ & $837(7)$ & $0(-)$ & $59,10(1)$ & $0,00(-)$ & $52,13(17)$ \\
\hline 8 & MC3 & $11,37(0)$ & $178,52(0)$ & $0,00^{(3)}(-)$ & $902.325(0)$ & $570(3)$ & $0(-)$ & $21,09(2)$ & $0,00(-)$ & $52,23(24)$ \\
\hline 9 & MC4 & $1,82(0)$ & $18,77(0)$ & $2,41(81)$ & $19.709(1)$ & $179(18)$ & $0(-)$ & $7,63(2)$ & $0,00(-)$ & $32,88(17)$ \\
\hline 10 & MC5 & $11,52(0)$ & $117,68(0)$ & $0,43(1.174)$ & $912.365(0)$ & $901(14)$ & $0(-)$ & $23,26(1)$ & $6,24(26)$ & $50,53(17)$ \\
\hline 11 & JF1 & $5,14(0)$ & $104,62(0)$ & $32,18(34)$ & $44.306(0)$ & $326(22)$ & $0(-)$ & $44,07(2)$ & $0,00(-)$ & $80,33(18)$ \\
\hline 12 & JF2 & $5,76(0,4)$ & $199,21(0)$ & $13,28(26)$ & $53.754(0)$ & $286(11)$ & $0(-)$ & $54,65(1)$ & $1,71(99)$ & $78,19(22)$ \\
\hline 13 & JF3 & $5,96(5,1)$ & $67,81(0)$ & $51,00(37)$ & $46.617(0)$ & $572(14)$ & $0(-)$ & $29,97(2)$ & $36,12(30)$ & $275,41(35)$ \\
\hline 14 & JF4 & $6,31(0)$ & $93,96(0)$ & $18,79(61)$ & $52.946(1)$ & $281(16)$ & $0(-)$ & $25,38(2)$ & $17,88(47)$ & $87,51(29)$ \\
\hline 15 & JF5 & $2,70(0)$ & $59,62(0)$ & $14,77(62)$ & $22.653(1)$ & $151(19)$ & $0(-)$ & $17,84(1)$ & $0,02(5.368)$ & $45,31(32)$ \\
\hline 16 & SG1 & $12,64(0)$ & $244,98(0)$ & $19,24(62)$ & $727.815(0)$ & $313(3)$ & $0(-)$ & $19,33(2)$ & $14,31(6)$ & $34,20(34)$ \\
\hline 17 & SG2 & $14,71(0)$ & $255,39(0)$ & $0,00(-)$ & $670.676(0)$ & $260(2)$ & $0(-)$ & $12,79(2)$ & $26,46(4)$ & $27,89(45)$ \\
\hline 18 & SG3 & $14,53(0)$ & $231,65(0)$ & $0,00(-)$ & $766.228(0)$ & $277(4)$ & $0(-)$ & $20,51(2)$ & $19,09(6)$ & $33,23(51)$ \\
\hline 19 & SG4 & $16,22(0)$ & $312,56(0)$ & $0,00(-)$ & $916.995(0)$ & $287(2)$ & $0(-)$ & $10,91(2)$ & $17,78(5)$ & $23,60(45)$ \\
\hline 20 & SG5 & $11,19(0)$ & $175,13(0)$ & $0,00(-)$ & $79.859(0)$ & $208(2)$ & $0(-)$ & $9,18(2)$ & $0,00(-)$ & $19,12(37)$ \\
\hline 21 & AR1 & $7,27(0)$ & $129,06(0)$ & $5,85(54)$ & $56.804(0)$ & $218(3)$ & $0(-)$ & $19,75(1)$ & $0,00(-)$ & $63,41(19)$ \\
\hline 22 & AR2 & $11,26(0,1)$ & $143,93(0)$ & $0,00(-)$ & $795.357(0)$ & $278(2)$ & $0(-)$ & $6,88(2)$ & $0,00(-)$ & $28,65(31)$ \\
\hline 23 & AR3 & $7,84(0)$ & $173,87(0)$ & $19,44(13)$ & $66.330(0)$ & $229(2)$ & $0(-)$ & $35,44(0)$ & $0,00(-)$ & $28,09(9)$ \\
\hline 24 & AR4 & $9,15(0,4)$ & $117,50(0)$ & $7,11(51)$ & $64.043(0)$ & $220(2)$ & $0(-)$ & $18,20(1)$ & $0,27(594)$ & $48,57(27)$ \\
\hline 25 & AR5 & $8,90(0,4)$ & $111,01(0)$ & $6,77(39)$ & $60.935(0)$ & $230(2)$ & $0(-)$ & $19,04(1)$ & $0,00(-)$ & $46,74(22)$ \\
\hline 26 & BM1 & $8,44(0)$ & $119,27(0)$ & $17,62(19)$ & $70.314(0)$ & $755(3)$ & $0(-)$ & $50,69(1)$ & $1,54(69)$ & $55,33(7)$ \\
\hline 27 & BM2 & $3,89(0)$ & $20,82(0)$ & $7,26(34)$ & $36.224(0)$ & $745(2)$ & $0(-)$ & $9,28(1)$ & $5,29(38)$ & $32,91(6)$ \\
\hline 28 & BM3 & $3,13(0)$ & $17,84(0,1)$ & $0,00(-)$ & $27.983(0)$ & $244(4)$ & $0(-)$ & $13,16(1)$ & $7,40(24)$ & $28,05(13)$ \\
\hline 29 & BM4 & $6,75(0)$ & $42,78(0,1)$ & $2,71(99)$ & $54.347(0)$ & $810(5)$ & $0(-)$ & $21,33(2)$ & $6,61(20)$ & $62,44(5)$ \\
\hline 30 & BM5 & $3,32(0)$ & $30,35(0,1)$ & $0,42(523)$ & $32.382(0)$ & $310(8)$ & $0(-)$ & $12,04(3)$ & $21,26(16)$ & $27,97(10)$ \\
\hline 31 & BR1 & $4,46(0)$ & $44,19(0)$ & $0,00(-)$ & $38.402(0)$ & $280(3)$ & $0(-)$ & $10,38(2)$ & $11,22(14)$ & $36,16(6)$ \\
\hline 32 & BR2 & $6,15(0)$ & $17,58(0)$ & $0,93(328)$ & $48.966(0)$ & $525(2)$ & $0(-)$ & $11,26(1)$ & $12,57(8)$ & $51,75(6)$ \\
\hline 33 & BR3 & $3,14(0)$ & $16,44(0)$ & $0,00(-)$ & $28.324(0)$ & $159(5)$ & $0(-)$ & $6,18(2)$ & $20,21(7)$ & $25,98(12)$ \\
\hline 34 & BR4 & $2,28(0)$ & $16,37(0,1)$ & $0,00(-)$ & 21.992(1) & $198(6)$ & $0(-)$ & $5,40(3)$ & $29,16(16)$ & $25,09(7)$ \\
\hline 35 & CA1 & $10,07(0)$ & $151,79(0)$ & $0,00(-)$ & $75.762(0)$ & $399(4)$ & $0(-)$ & $9,69(2)$ & $4,30(18)$ & $26,88(13)$ \\
\hline 36 & $\mathrm{CA} 2$ & $10,11(0)$ & $159,39(0)$ & $0,00(-)$ & $80.891(0)$ & $341(3)$ & $0(-)$ & $9,94(1)$ & $3,70(17)$ & $19,49(12)$ \\
\hline 37 & $\mathrm{CA} 3$ & $9,58(0)$ & $139,37(0)$ & $7,93(61)$ & $856.317(0)$ & $544(4)$ & $0(-)$ & $17,23(1)$ & $7,71(35)$ & $50,45(11)$ \\
\hline 38 & CA4 & $10,01(0)$ & $159,90(0)$ & $0,00(-)$ & $929.143(0)$ & $405(2)$ & $0(-)$ & $14,23(1)$ & $4,14(28)$ & $37,74(7)$ \\
\hline 39 & CA5 & $3,88(0)$ & $82,78(0)$ & $0,00(-)$ & $36.172(0)$ & $94(8)$ & $0(-)$ & $10,44(1)$ & $3,43(40)$ & $25,50(24)$ \\
\hline 40 & $\mathrm{CA} 6$ & $4,04(0)$ & $64,92(0)$ & $0,41(793)$ & $35.005(0)$ & $138(9)$ & $0(-)$ & $15,83(1)$ & $0,00(-)$ & $24,05(9)$ \\
\hline 41 & $\mathrm{CA} 7$ & $7,55(0)$ & $120,92(0)$ & $28,97(13)$ & $66.263(0)$ & $1.148(1)$ & $0(-)$ & $63,53(0)$ & $1,32(51)$ & $61,04(4)$ \\
\hline 42 & CA8 & $7,41(0)$ & $38,93(0)$ & $12,02(33)$ & $58.322(0)$ & $419(2)$ & $0(-)$ & $12,76(1)$ & $0,06(1.134)$ & $41,72(8)$ \\
\hline 43 & $\mathrm{CA} 9$ & $4,56(0)$ & $94,88(0)$ & $12,59(41)$ & $43.466(0)$ & $135(6)$ & $0(-)$ & $37,04(0)$ & $6,12(28)$ & $28,49(15)$ \\
\hline 44 & CA10 & $4,38(0)$ & $67,89(0)$ & $4,87(66)$ & $41.157(0)$ & $127(6)$ & $0(-)$ & $15,36(1)$ & $1,15(87)$ & $22,20(19)$ \\
\hline 45 & CA11 & $9,70(0)$ & $94,12(0)$ & $32,63(12)$ & $80.821(0)$ & $321(3)$ & $0(-)$ & $20,81(0)$ & $3,68(30)$ & $36,94(6)$ \\
\hline 46 & CA12 & $8,40(0)$ & $154,45(0)$ & $17,66(32)$ & $74.474(0)$ & $207(5)$ & $0(-)$ & $28,01(0)$ & $13,82(10)$ & $27,22(8)$ \\
\hline 47 & CA13 & $3,45(0)$ & $67,90(0)$ & $10,43(37)$ & $30.087(0)$ & $152(7)$ & $0(-)$ & $15,59(1)$ & $5,44(92)$ & $21,23(9)$ \\
\hline 48 & CA14 & $3,80(0)$ & $89,16(0)$ & $5,57(58)$ & $36.598(0)$ & $108(9)$ & $0(-)$ & $15,86(1)$ & $1,62(76)$ & $27,00(14)$ \\
\hline 49 & CA15 & $3,57(0)$ & $50,71(0)$ & $0,00(-)$ & $33.624(0)$ & $108(5)$ & $0(-)$ & $7,13(1)$ & $0,00(-)$ & $13,07(7)$ \\
\hline 50 & CA16 & $3,30(0)$ & $39,93(0)$ & $0,00(-)$ & $32.700(0)$ & $93(3)$ & $0(-)$ & $7,87(1)$ & $0,00(-)$ & $16,50(12)$ \\
\hline 51 & BA1 & $3,56(0)$ & $63,58(0)$ & $10,24(58)$ & $33.190(0)$ & $151(8)$ & $0(-)$ & $29,33(1)$ & $0,00(-)$ & $15,25(15)$ \\
\hline 52 & $\mathrm{BA} 2$ & $4,84(0)$ & $59,79(0)$ & $6,77(40)$ & $42.412(0)$ & $176(4)$ & $0(-)$ & $27,28(0)$ & $1,21(128)$ & $25,01(10)$ \\
\hline 53 & $\mathrm{BA} 3$ & $4,19(0)$ & $37,08(0)$ & $13,71(22)$ & $36.998(0)$ & $109(4)$ & $0(-)$ & $8,70(1)$ & $0,00(-)$ & $15,92(17)$ \\
\hline 54 & BA4 & $7,59(0)$ & $159,80(0)$ & $9,15(83)$ & $65.065(0)$ & $465(3)$ & $0(-)$ & $19,76(2)$ & $0,06(1.583)$ & $27,83(10)$ \\
\hline 55 & BA5 & $4,75(0)$ & $142,91(0)$ & $11,60(38)$ & $46.386(0)$ & $145(7)$ & $0(-)$ & $28,52(1)$ & $0,00(-)$ & $19,72(13)$ \\
\hline 56 & BA6 & $3,17(0)$ & $52,51(0)$ & $0,00(-)$ & $29.648(0)$ & $70(5)$ & $0(-)$ & $5,63(1)$ & $1,08(154)$ & $14,99(25)$ \\
\hline 57 & BA7 & $4,46(0)$ & $162,63(0)$ & $21,95(35)$ & $44.373(0)$ & $222(7)$ & $0(-)$ & $34,05(1)$ & $3,06(43)$ & $16,79(15)$ \\
\hline
\end{tabular}


Tabela 1. (continuação)

\begin{tabular}{|c|c|c|c|c|c|c|c|c|c|c|}
\hline \multirow{2}{*}{$\mathrm{N}^{0}$} & \multirow{2}{*}{ Id } & Cd & $\mathrm{Cr}$ & $\mathrm{Cu}$ & $\mathrm{Fe}$ & $M n$ & Mo & $\mathrm{Ni}$ & $\mathrm{Pb}$ & Zn \\
\hline & & \multicolumn{9}{|c|}{$\mathrm{mg} \mathrm{kg}^{-1}$} \\
\hline 58 & BA8 & $3,59(0)$ & $128,89(0)$ & $20,32(21)$ & $35.152(0)$ & $140(5)$ & $0(-)$ & $40,83(1)$ & $1,36(180)$ & $29,15(10)$ \\
\hline 59 & BA9 & $4,43(0)$ & $121,39(0)$ & $1,32(228)$ & $41.883(0)$ & $325(5)$ & $0(-)$ & $10,00(2)$ & $0,00(-)$ & $23,65(15)$ \\
\hline 60 & BA10 & $4,19(0)$ & $114,60(0)$ & $12,12(45)$ & $40.117(0)$ & $157(5)$ & $0(-)$ & $29,45(1)$ & $2,15(74)$ & $17,74(20)$ \\
\hline 61 & LD1 & $6,91(0)$ & $273,99(0)$ & $29,91(16)$ & $61.217(0)$ & $273(6)$ & $0(-)$ & $62,85(0)$ & $1,42(79)$ & $54,92(14)$ \\
\hline 62 & LD2 & $2,99(0)$ & $185,15(0)$ & $23,16(31)$ & $24.210(0)$ & $198(10)$ & $0(-)$ & $57,67(1)$ & $0,00(-)$ & $40,99(13)$ \\
\hline 63 & LD3 & $6,86(0)$ & $199,84(0)$ & $13,10(32)$ & $61.435(0)$ & $232(5)$ & $0(-)$ & $38,18(1)$ & $1,95(41)$ & $35,72(12)$ \\
\hline 64 & LD4 & $5,25(0)$ & $125,35(0)$ & $16,20(32)$ & $48.940(0)$ & $178(6)$ & $0(-)$ & $32,61(1)$ & $0,17(577)$ & $36,81(25)$ \\
\hline 65 & LD5 & $5,44(0)$ & $87,51(0)$ & $15,39(38)$ & $48.095(0)$ & $242(7)$ & $0(-)$ & $12,21(2)$ & $0,16(1.967)$ & $20,89(12)$ \\
\hline 66 & LD6 & $8,59(0)$ & $139,98(0)$ & $0,00(-)$ & $72.726(0)$ & $253(4)$ & $0(-)$ & $4,10(3)$ & $0,60(278)$ & $8,33(15)$ \\
\hline 67 & LD7 & $3,94(0)$ & $13,47(0)$ & $18,73(23)$ & $35.703(0)$ & $283(5)$ & $0(-)$ & $6,20(2)$ & $0,00(-)$ & $36,76(13)$ \\
\hline 68 & LD8 & $7,29(0)$ & $197,52(0)$ & $32,96(24)$ & $64.623(0)$ & $390(5)$ & $0(-)$ & $33,79(1)$ & $0,00(-)$ & $33,70(13)$ \\
\hline 69 & LD9 & $7,58(0)$ & $17,25(0)$ & $37,16(17)$ & $60.617(0)$ & $540(3)$ & $0(-)$ & $10,00(1)$ & $0,00(-)$ & $49,69(9)$ \\
\hline 70 & LD10 & $3,95(0)$ & $22,49(0)$ & $15,31(27)$ & $34.628(0)$ & $197(5)$ & $0(-)$ & $6,86(1)$ & $0,00(-)$ & $34,96(13)$ \\
\hline 71 & $\mathrm{C} 01$ & $7,46(0)$ & $105,23(0)$ & $18,64(24)$ & $64.750(0)$ & $527(12)$ & $0(-)$ & $32,09(2)$ & $0,00(-)$ & $73,77(24)$ \\
\hline 72 & C02 & $6,70(0)$ & $69,02(0)$ & $10,07(28)$ & $55.036(0)$ & $320(3)$ & $0(-)$ & $23,86(1)$ & $0,00(-)$ & $34,47(14)$ \\
\hline 73 & $\mathrm{CO3}$ & $6,24(0)$ & $57,75(0)$ & $8,46(34)$ & $50.557(0)$ & $908(9)$ & $0(-)$ & $22,30(1)$ & $10,59(10)$ & $35,69(12)$ \\
\hline 74 & CO4 & $8,70(0)$ & $411,65(0)$ & $26,82(13)$ & $66.560(0)$ & $870(7)$ & $0(-)$ & $85,27(1)$ & $1,16(78)$ & $47,38(9)$ \\
\hline 75 & $\mathrm{CO5}$ & $7,35(0)$ & $52,49(0)$ & $9,05(27)$ & $56.834(0)$ & $608(8)$ & $0(-)$ & $22,22(1)$ & $10,61(16)$ & $39,31(12)$ \\
\hline 76 & SJ1 & $5,80(0)$ & $111,02(0)$ & $4,07(58)$ & $46.510(0)$ & $277(3)$ & $0(-)$ & $16,44(0)$ & $1,10(176)$ & $23,43(15)$ \\
\hline 77 & SJ2 & $1,88(0)$ & $47,37(0)$ & $18,61(42)$ & $184.021(0)$ & $278(18)$ & $0(-)$ & $16,05(2)$ & $10,78(32)$ & $50,05(18)$ \\
\hline 78 & SJ3 & $2,61(0)$ & $53,29(0)$ & $11,19(20)$ & $26.913(0)$ & $214(13)$ & $0(-)$ & $25,35(0)$ & $16,26(23)$ & $26,82(9)$ \\
\hline 79 & SJ4 & $6,21(0)$ & $151,14(0)$ & $0,00(-)$ & $55.040(0)$ & $120(1)$ & $0(-)$ & $14,11(0)$ & $0,00(-)$ & $9,57(15)$ \\
\hline 80 & SJ5 & $5,69(0)$ & $125,81(0)$ & $0,00(-)$ & $50.907(0)$ & $175(2)$ & $0(-)$ & $14,658(0)$ & $0,00(-)$ & $13,14(20)$ \\
\hline
\end{tabular}

${ }^{1}$ Município de coleta: AR: Araxá, BA: Barbacena, BR: Bom Repouso, BM: Borda da Mata, CA: Carandaí, Co: Coimbra, JF: Juiz de Fora, LD:Lagoa Dourada, MC: Mário Campos, SG: São Gotardo, SJ: São João del Rei e Vl: Viçosa

2 Índice de disponibilidade: percentual do teor disponível (DTPA) em relação ao teor total

${ }^{3}$ Valores referidos como iguais a zero não indicam, obrigatoriamente, ausência dos elementos analisados e, sim, que os teores não atingiram o limite de deteç̧ão do equipamento ICP-OES

Tabela 2. Valores orientadores de referência de qualidade (VRQ), de prevenção (VP) e intervenção (VI) para alguns metais pesados no Estado de São Paulo (CETESB, 2005)

\begin{tabular}{cccccc}
\hline & \multicolumn{5}{c}{ Solos } \\
\cline { 2 - 6 } Elemento & VRQ & VP & \multicolumn{4}{c}{ VI } \\
\cline { 2 - 6 } & & & Agrícola & Residencial & Industrial \\
\cline { 2 - 6 } $\mathrm{Cd}$ & $<0,5$ & 1,3 & 3 & 8 & 20 \\
$\mathrm{~Pb}$ & 17 & 72 & 180 & 300 & 900 \\
$\mathrm{Cu}$ & 35 & 60 & 200 & 400 & 600 \\
$\mathrm{Cr}$ & 40 & 75 & 150 & 300 & 400 \\
$\mathrm{Fe}$ & - & - & - & - & - \\
$\mathrm{Mn}$ & - & - & - & - & - \\
$\mathrm{Mo}$ & $<$ & 30 & 50 & 100 & 120 \\
$\mathrm{Ni}$ & 13 & 30 & 70 & 100 & 130 \\
\hline $\mathrm{Zn}$ & 60 & 300 & 450 & 1.000 & 2.000 \\
\hline
\end{tabular}

de contaminação acima do qual existem riscos potenciais, diretos ou indiretos, à saúde humana e, quando excedido, a área será classificada contaminada sob investigação, indicando a necessidade de ações de intervenção (CETESB, 2005). Nesta análise foram desconsiderados os teores de Fe e $\mathrm{Mn}$, por serem elementos comuns na composição de muitos componentes da fase sólida do solo.

À exceção do $\mathrm{Zn}$ e $\mathrm{Pb}$, todos os demais metais pesados apresentaram em algum ponto de amostragem, teor superior ao VP. A situação pode ser considerada mais preocupante ainda uma vez que os elementos $\mathrm{Cd}$, Cr e Ni foram diagnosticados em ao menos uma amostra com teor superior ao
VI agrícola, denotando a necessidade de mais estudos nessas áreas, de forma a subsidiar e direcionar trabalhos de remediação.

Dada as conseqüências legais e ambientais de tais achados, ressalta-se que os resultados foram obtidos a partir de uma única amostra composta e tiveram caráter exploratório e preliminar. Conclusões definitivas acerca desses maiores teores observados devem ser tomadas com cautela, devendo ser precedidas de análise mais intensa dos pontos de coleta com problemas, a partir de um número maior de amostras.

Dos elementos com teores acima do VI agrícola, o Ni foi o de menor ocorrência, com apenas uma amostra (CO4) superando este limite. Na seqüência vem o Cr, com 21 amostras com teores acima do VI. O elemento com maior número de ocorrência de teores superiores ao VI foi o Cd, com seis amostras em que esse limite não foi superado.

Embora os dados obtidos, principalmente de $\mathrm{Cr}$ e Cd, indiquem uma situação de contaminação ambiental, merece ressalva que os limites considerados são os recomendados para o Estado de São Paulo e não para Minas Gerais, o que reforça a necessidade do estabelecimento de valores orientadores por unidade da Federação, de forma a contemplar adequadamente a variabilidade de solos de cada Estado. Destaca-se ainda que a situação aqui constatada não seria verificada até bem pouco tempo atrás, uma vez que os valores orientadores de São Paulo foram recentemente alterados (CETESB, 2005). Na classificação anterior, de 2001, a situação seria mais amena, com o Cr e Cd apresentando, respectivamente, apenas 2 e 12 amostras com teores além do 
VI. A redução dos limites de 300 para $150 \mathrm{mg} \mathrm{kg}^{-1}$ e de 10 para $3 \mathrm{mg} \mathrm{kg}^{-1}$ para $\mathrm{Cr}$ e $\mathrm{Cd}$, respectivamente, foi decisiva para os achados e demonstram a necessidade de revisão constante dos valores orientadores e a definição de valores próprios de cada Estado, adaptados a cada realidade.

Analisando-se as amostras identificadas com problemas de contaminação, que já exigiriam programas de remediação, não se verifica, à luz das informações coletadas em campo, qualquer indício de que determinada fonte de nutrientes ou corretivo pudesse ser associada ao aumento do teor de metais pesados. Neste ponto, ressalta-se a falta de uma amostragem no entorno das áreas agrícolas estudadas e em local menos perturbado, para permitir comparações mais adequadas com os teores naturalmente presentes.

Ainda que alguns teores tenham superado os limites legais, de forma geral os valores médios observados são próximos dos obtidos via análise de fluorescência, por Marques et al. (2004), para solos do cerrado brasileiro, à exceção dos valores máximos para $\mathrm{Cr}$, Ni e Zn. Os dados concordam também com os verificados por Ramalho et al. (2000), à exceção dos teores máximos verificados para o Ni, Mn, Cd e Cu, mas, por outro lado, discordam dos obtidos por Duarte \& Pasqual (2000) para solos paulistas.

\section{Teores disponíveis de metais pesados nos solos, extraídos com DTPA}

Os teores de metais pesados disponíveis com potencial de serem absorvidos pelas plantas e com implicações diretas e indiretas sobre a saúde humana apresentaram, de maneira geral, baixos valores. Muito embora alguns elementos, em especial Cd e Cr, tenham apresentado teores totais relativamente elevados, os teores disponíveis obtidos indicam que apenas uma pequena parte pode ser considerada passível de ser absorvida pelas plantas, como indicado pelos dados do índice de disponibilidade (Tabela 1). Os elementos Cd, Cr e Ni exibiram valores desprezíveis de disponibilidade, com índices de disponibilidade próximos a zero; já o $\mathrm{Cu}, \mathrm{Pb}$ e Zn indicaram percentuais disponíveis mais expressivos em relação aos teores totais estimados.

Esses resultados diferem um pouco daqueles apresentados por Gomes et al. (2001) e Fontes \& Gomes (2003) que, estudando adsorção competitiva, constataram que $\mathrm{Cu}$ e $\mathrm{Pb}$ seriam extremamente retidos pelo solo enquanto $\mathrm{Cd}$ e $\mathrm{Ni}$ não o seriam; já os elementos $\mathrm{Cr}$ e Zn se comportaram de acordo com o observado nesses estudos.

Alguns índices de disponibilidade exibem valores absurdos para os elementos $\mathrm{Cu}$ e $\mathrm{Pb}$, muito próximos ou mesmo superiores a $100 \%$, o que pode ser atribuído a erros analíticos, principalmente associados aos baixos teores totais observados nessas amostras de elevado percentual disponível.

\section{Teores totais de metais pesados nos vegetais}

Os teores de metais pesados dos vegetais coletados no campo (Tabela 3) foram semelhantes aos observados nas amostras recolhidas na CEASA-MG (Tabela 4). Considerando-se o conjunto de dados, os teores mínimos e máximos ( $\mathrm{mg} \mathrm{kg}^{-1}$ matéria seca) observados foram de: 0,000 a 0,480 para o Cd; 0,253 a 2,053 para o Cr; 0,440 a 37,400 para o $\mathrm{Cu} ; 12,613$ a 627,053 para o $\mathrm{Fe}$; 3,267 a 571,547 para o $\mathrm{Mn}$; 0,000 a 2,667 para o Mo; 0,013 a 1,533 para o $\mathrm{Ni} ; 0,000$ a 331,600 para o $\mathrm{Pb}$ e 8,840 a 115,36 para o Zn.

Os teores totais nos vegetais foram superiores aos verificados por Ramalho et al. (2000) em uma microbacia com uso intensivo de agroquímicos, porém, os resultados obtidos para Cd, Cr, Mo e Ni não se aproximam dos limites críticos (LC) definidos por Alloway (1997), a partir de compilação de Kabata-Pendias \& Pendias (1992), como as concentrações na planta acima das quais a toxicidade é possível. No caso dos metais citados, esses limites seriam, em mg kg-1 de matéria seca, de: 5 a 30 para o Cd e Cr, 10 a 50 para o Mo e, 10 a 100 para o Ni. Para os demais elementos, poucas amostras ultrapassaram os limites inferiores considerados: para o $\mathrm{Cu}$ (LC: 20 a $100 \mathrm{mg} \mathrm{kg}^{-1}$ ), apenas uma amostra de campo (AL5/VI5) e uma do CEASA (AL3/BR); para o Mn (LC: 300 a $500 \mathrm{mg} \mathrm{kg}^{-1}$ ), uma amostra de campo (AL4/VI4) e uma do CEASA (AL5/BE); para o Pb (LC: 30 a $300 \mathrm{mg} \mathrm{kg}^{-1}$ ), duas amostras de campo (AL7/ MC2 e RE12/LD2) e três do CEASA (CE16/LD, CE19/LD e BE4/CG) e, para o Zn (LC: 100 a $400 \mathrm{mg} \mathrm{kg}^{-1}$ ), só uma amostra do CEASA (BE7/QU). De todas as amostras analisadas, apenas uma (RE17/SJ) superou o limite superior da faixa do limite crítico para o $\mathrm{Pb}$.

A legislação brasileira não disciplina limites críticos para olerícolas com vistas ao consumo humano. A única referência encontrada foi a Portaria ${ }^{\circ}$ 685/1998, da Agência Nacional de Vigilância Sanitária (ANVISA, 2004); nessa norma, apenas o elemento Cu é contemplado em termos de produtos hortícolas, com limite de $10 \mathrm{mg} \mathrm{kg}^{-1}$ de peso fresco. Considerando-se este limite e o conjunto de vegetais analisados $(\mathrm{n}=194)$, apenas seis amostras de alface, duas de beterraba e uma de tomate, superaram o limite; entretanto, os dados deste trabalho são expressos em peso seco e se considerando a umidade média desses vegetais in natura (NEPA, 2004), admite-se que nenhuma das amostras analisadas apresenta problemas de contaminação para este elemento.

\section{Teores totais de metais pesados nas águas}

Os dados obtidos indicaram que o único elemento não identificado nas águas amostradas foi o $\mathrm{Pb}$ (Tabela 5); os demais metais pesados foram observados, em pelo menos uma amostra, embora os teores tenham sido, de forma geral, muito baixos. Os teores mínimos e máximos $\left(\mathrm{mg} \mathrm{L}^{-1}\right)$ observados foram de 0,000 a 0,001 para o Cd (média de $0,000) ; 0,000$ a $0,297(0,011)$ para o $\mathrm{Cr} ; 0,000$ a 0,067 para o $\mathrm{Cu}(0,004) ; 0,018$ a 14,228 para o Fe $(2,158) ; 0,000$ a 0,639 para o $\mathrm{Mn}(0,111) ; 0,000$ a 0,002 para o Mo $(0,000)$; 0,000 a 0,060 para o $\mathrm{Ni}(0,004)$ e 0,000 a 0,129 para o $\mathrm{Zn}$ $(0,010)$. Esses teores são muito inferiores aos verificados por Ramalho et al. (2000) em dois córregos da microbacia Caetés, no Rio de Janeiro, com intensiva utilização de agroquímicos.

Ainda que se tenha recolhido apenas uma amostra por ponto de análise, que foi coletada em um único dia, considera-se que os dados obtidos são interessantes pela dimensão 
Tabela 3. Teores totais de metais pesados em olerícolas coletadas no Estado de Minas Gerais

\begin{tabular}{|c|c|c|c|c|c|c|c|c|c|c|c|}
\hline \multirow{2}{*}{$\mathbf{N}^{0}$} & \multirow{2}{*}{$\operatorname{ld}(1)$} & \multirow{2}{*}{$\operatorname{ld}^{(2)}$} & Cd & $\mathrm{Cr}$ & $\mathrm{Cu}$ & $\mathrm{Fe}$ & $\mathrm{Mn}$ & Mo & $\mathrm{Ni}$ & $\mathrm{Pb}$ & $\mathrm{Zn}$ \\
\hline & & & \multicolumn{9}{|c|}{$\mathrm{mg} \mathrm{kg}^{-1}$} \\
\hline \multicolumn{12}{|c|}{ Alface } \\
\hline 1 & AL1 & Vl1 & 0,040 & 1,653 & 5,080 & 106,253 & 27,987 & 0,587 & 0,093 & 9,640 & 33,800 \\
\hline 2 & AL2 & VI2 & 0,040 & 1,373 & 4,440 & 74,253 & 47,547 & 0,067 & 0,133 & 1,360 & 30,120 \\
\hline 3 & AL3 & VI3 & 0,080 & 1,453 & 4,360 & 110,253 & 29,667 & 0,147 & 0,133 & 2,080 & 39,360 \\
\hline 4 & AL4 & VI4 & 0,120 & 1,613 & 6,240 & 78,653 & 571,547 & 0,027 & 0,333 & 1,520 & 64,560 \\
\hline 5 & AL5 & VI5 & 0,080 & 1,453 & 37,400 & 66,253 & 70,747 & 0,107 & 0,093 & 0,440 & 44,560 \\
\hline 6 & AL6 & MC1 & 0,040 & 1,493 & 8,560 & 175,853 & 63,147 & 0,067 & 0,213 & 0,560 & 30,080 \\
\hline 7 & AL7 & MC2 & 0,040 & 0,693 & 7,000 & 139,453 & 50,347 & 0,147 & 0,773 & 66,400 & 29,720 \\
\hline 8 & AL8 & MC3 & 0,160 & 0,733 & 3,760 & 189,053 & 34,307 & 0,347 & 0,213 & 2,520 & 43,360 \\
\hline 9 & AL9 & MC4 & 0,120 & 0,693 & 4,800 & 154,653 & 179,947 & $0,000^{(3)}$ & 0,413 & 1,520 & 74,160 \\
\hline 10 & AL10 & MC5 & 0,120 & 0,733 & 4,320 & 221,053 & 146,347 & 0,107 & 0,293 & 0,000 & 36,040 \\
\hline 11 & AL11 & JF1 & 0,200 & 0,973 & 6,640 & 204,653 & 25,587 & 0,307 & 0,773 & 0,480 & 31,520 \\
\hline 12 & AL12 & $\mathrm{JF2}$ & 0,240 & 0,893 & 10,480 & 137,053 & 19,947 & 0,307 & 0,413 & 17,600 & 63,360 \\
\hline 13 & AL13 & JF3 & 0,480 & 0,893 & 13,400 & 205,053 & 30,907 & 2,667 & 0,973 & 2,320 & 74,960 \\
\hline 14 & AL14 & JF4 & 0,200 & 0,773 & 5,160 & 106,653 & 56,347 & 0,427 & 0,253 & 0,440 & 80,560 \\
\hline 15 & AL15 & JF5 & 0,080 & 0,733 & 5,040 & 103,453 & 27,867 & 0,307 & 0,093 & 1,280 & 32,160 \\
\hline \multicolumn{12}{|c|}{ Batata } \\
\hline 16 & BA1 & AR1 & 0,040 & 0,573 & 2,560 & 33,573 & 5,707 & 0,027 & 0,133 & 0,000 & 10,760 \\
\hline 17 & BA2 & AR2 & 0,040 & 0,533 & 1,920 & 18,933 & 4,507 & 0,107 & 0,133 & 0,000 & 12,120 \\
\hline 18 & BA3 & AR3 & 0,160 & 0,733 & 2,880 & 36,853 & 4,907 & 0,000 & 0,533 & 0,000 & 9,080 \\
\hline 19 & BA4 & AR4 & 0,120 & 0,493 & 2,200 & 16,413 & 4,227 & 0,187 & 0,053 & 0,000 & 12,360 \\
\hline 20 & BA5 & AR5 & 0,080 & 0,493 & 1,800 & 12,613 & 4,067 & 0,067 & 0,093 & 0,000 & 10,720 \\
\hline 21 & BA6 & BM1 & 0,040 & 0,813 & 3,000 & 29,133 & 8,387 & 0,027 & 0,253 & 0,000 & 14,360 \\
\hline 22 & BA7 & BM2 & 0,040 & 0,573 & 3,520 & 29,533 & 5,427 & 0,027 & 0,133 & 0,000 & 14,480 \\
\hline 23 & BA8 & BM3 & 0,000 & 0,533 & 5,880 & 25,373 & 3,827 & 0,000 & 0,173 & 0,000 & 14,560 \\
\hline 24 & BA9 & BM4 & 0,000 & 0,493 & 4,120 & 20,373 & 7,587 & 0,027 & 0,133 & 0,000 & 16,040 \\
\hline 25 & BA10 & BM5 & 0,080 & 0,533 & 4,520 & 36,413 & 11,347 & 0,147 & 0,453 & 0,000 & 15,160 \\
\hline 26 & BA11 & BR1 & 0,040 & 0,613 & 3,720 & 30,533 & 8,347 & 0,067 & 0,253 & 0,000 & 13,480 \\
\hline 27 & BA12 & BR2 & 0,040 & 0,573 & 2,880 & 24,133 & 5,387 & 0,067 & 0,133 & 0,000 & 14,280 \\
\hline 28 & BA13 & BR3 & 0,080 & 0,653 & 3,680 & 49,053 & 14,827 & 0,000 & 0,493 & 0,000 & 15,040 \\
\hline 29 & BA14 & BR4 & 0,000 & 0,533 & 2,040 & 43,453 & 12,307 & 0,067 & 0,213 & 0,000 & 14,640 \\
\hline \multicolumn{12}{|c|}{ Beterraba } \\
\hline 30 & BE1 & LD1 & 0,160 & 0,573 & 3,720 & 55,853 & 39,547 & 0,027 & 0,253 & 0,000 & 33,960 \\
\hline 31 & BE2 & LD3 & 0,080 & 0,573 & 5,480 & 41,053 & 42,747 & 0,067 & 0,413 & 0,000 & 44,160 \\
\hline 32 & BE3 & LD5 & 0,160 & 0,613 & 5,960 & 46,253 & 122,747 & 0,147 & 1,373 & 0,000 & 34,360 \\
\hline 33 & BE4 & LD7 & 0,080 & 0,653 & 2,040 & 41,453 & 17,547 & 0,000 & 0,573 & 0,000 & 18,120 \\
\hline 34 & BE5 & LD9 & 0,040 & 0,653 & 3,080 & 59,053 & 22,427 & 0,027 & 0,333 & 0,000 & 25,200 \\
\hline 35 & BE6 & SJ1 & 0,040 & 0,533 & 2,320 & 37,693 & 8,867 & 0,107 & 0,053 & 0,000 & 20,760 \\
\hline 36 & BE7 & SJ2 & 0,040 & 0,533 & 3,520 & 28,453 & 4,987 & 0,027 & 0,013 & 0,000 & 14,000 \\
\hline 37 & BE8 & SJ3 & 0,000 & 0,573 & 1,960 & 32,573 & 6,267 & 0,027 & 0,133 & 0,000 & 19,080 \\
\hline 38 & BE9 & SJ4 & 0,040 & 0,613 & 11,920 & 37,173 & 6,227 & 0,027 & 0,053 & 0,000 & 21,440 \\
\hline 39 & BE10 & SJ5 & 0,040 & 0,573 & 5,480 & 28,453 & 10,507 & 0,027 & 0,093 & 0,000 & 21,920 \\
\hline \multicolumn{12}{|c|}{ Cenoura } \\
\hline 40 & CE1 & SG1 & 0,040 & 0,453 & 4,840 & 21,133 & 11,147 & 0,227 & 0,253 & 0,000 & 13,920 \\
\hline 41 & CE2 & SG2 & 0,040 & 0,533 & 4,280 & 30,253 & 16,027 & 0,067 & 0,093 & 0,000 & 12,760 \\
\hline 42 & CE3 & SG3 & 0,080 & 0,613 & 7,600 & 48,253 & 15,307 & 0,267 & 0,213 & 0,000 & 23,040 \\
\hline 43 & CE4 & SG4 & 0,040 & 0,613 & 6,480 & 51,853 & 15,427 & 0,147 & 0,573 & 0,000 & 17,160 \\
\hline 44 & CE5 & SG5 & 0,040 & 0,573 & 5,080 & 49,453 & 11,107 & 0,347 & 0,213 & 0,000 & 19,840 \\
\hline 45 & CE6 & CA2 & 0,080 & 0,613 & 6,400 & 36,653 & 23,467 & 0,027 & 0,613 & 0,000 & 29,720 \\
\hline 46 & CE7 & CA3 & 0,080 & 0,613 & 3,080 & 41,053 & 14,347 & 0,387 & 0,333 & 0,000 & 21,720 \\
\hline 47 & CE8 & CA4 & 0,040 & 0,373 & 3,960 & 44,653 & 28,267 & 0,027 & 0,413 & 0,000 & 23,920 \\
\hline 48 & CE9 & CA5 & 0,040 & 1,293 & 1,240 & 38,093 & 12,267 & 0,507 & 0,293 & 0,000 & 21,680 \\
\hline 49 & CE10 & CA15 & 0,040 & 0,333 & 7,720 & 37,453 & 23,587 & 0,067 & 0,693 & 0,000 & 24,840 \\
\hline \multicolumn{12}{|c|}{ Repolho } \\
\hline 50 & RE1 & CA1 & 0,000 & 0,293 & 7,840 & 38,893 & 21,267 & 0,000 & 0,413 & 0,000 & 18,680 \\
\hline 51 & RE2 & CA6 & 0,080 & 0,333 & 6,360 & 32,413 & 15,427 & 0,067 & 0,253 & 0,000 & 22,840 \\
\hline 52 & RE3 & CA7 & 0,000 & 0,253 & 0,440 & 22,373 & 11,427 & 0,307 & 0,213 & 0,000 & 11,400 \\
\hline 53 & RE4 & СA9 & 0,040 & 0,333 & 7,640 & 45,053 & 10,907 & 0,147 & 0,133 & 0,000 & 24,880 \\
\hline
\end{tabular}


Tabela 3. (continuação)

\begin{tabular}{|c|c|c|c|c|c|c|c|c|c|c|c|}
\hline \multirow{2}{*}{$\mathbf{N}^{0}$} & \multirow{2}{*}{$\operatorname{ld}^{(1)}$} & \multirow{2}{*}{ Id(2) } & $\mathrm{Cd}$ & $\mathrm{Cr}$ & $\mathrm{Cu}$ & $\mathrm{Fe}$ & $M n$ & Mo & $\mathrm{Ni}$ & $\mathrm{Pb}$ & $\mathrm{Zn}$ \\
\hline & & & \multicolumn{9}{|c|}{$\mathrm{mg} \mathrm{kg}^{-1}$} \\
\hline 54 & RE5 & CA13 & 0,040 & 0,293 & 0,480 & 17,973 & 10,587 & 0,267 & 0,013 & 0,000 & 13,320 \\
\hline 55 & RE6 & CA16 & 0,000 & 0,293 & 1,280 & 54,253 & 26,347 & 0,547 & 0,453 & 0,000 & 29,720 \\
\hline 56 & RE7 & BA2 & 0,040 & 1,533 & 3,480 & 53,453 & 14,787 & 0,027 & 0,373 & 0,000 & 23,400 \\
\hline 57 & RE8 & BA4 & 0,000 & 0,333 & 3,480 & 32,053 & 3,267 & 0,000 & 0,253 & 0,000 & 10,880 \\
\hline 58 & RE9 & BA6 & 0,040 & 0,253 & 2,720 & 23,293 & 14,427 & 0,027 & 0,093 & 0,000 & 18,320 \\
\hline 59 & RE10 & BA8 & 0,040 & 0,333 & 4,280 & 28,413 & 10,987 & 0,000 & 1,053 & 0,000 & 28,440 \\
\hline 60 & RE11 & BA10 & 0,040 & 0,333 & 1,360 & 41,853 & 39,027 & 0,107 & 0,693 & 0,000 & 20,520 \\
\hline 61 & RE12 & LD2 & 0,000 & 0,293 & 1,400 & 16,933 & 9,827 & 0,347 & 0,213 & 38,160 & 10,720 \\
\hline 62 & RE13 & LD4 & 0,040 & 1,293 & 7,200 & 40,253 & 7,307 & 0,227 & 0,373 & 0,000 & 17,480 \\
\hline 63 & RE14 & LD6 & 0,080 & 0,333 & 1,000 & 32,053 & 13,707 & 0,107 & 0,253 & 0,000 & 23,440 \\
\hline 64 & RE15 & LD8 & 0,080 & 0,373 & 8,080 & 57,853 & 14,947 & 0,067 & 0,933 & 0,000 & 26,000 \\
\hline 65 & RE16 & LD10 & 0,040 & 0,413 & 6,440 & 32,733 & 7,987 & 0,067 & 0,413 & 0,000 & 16,080 \\
\hline \multicolumn{12}{|c|}{ Tomate } \\
\hline 66 & T01 & CA8 & 0,040 & 0,653 & 5,760 & 65,053 & 12,587 & 0,107 & 0,493 & 0,000 & 13,640 \\
\hline 67 & T02 & CA10 & 0,000 & 0,253 & 0,920 & 34,853 & 12,347 & 0,107 & 0,293 & 0,000 & 18,080 \\
\hline 68 & T03 & CA11 & 0,040 & 0,293 & 6,560 & 30,013 & 8,667 & 0,067 & 0,293 & 0,000 & 14,280 \\
\hline 69 & T04 & CA12 & 0,040 & 0,333 & 4,880 & 25,853 & 12,147 & 0,000 & 0,133 & 0,000 & 20,280 \\
\hline 70 & T05 & CA14 & 0,040 & 0,293 & 1,400 & 41,853 & 16,707 & 0,667 & 0,293 & 0,000 & 19,200 \\
\hline 71 & T06 & BA1 & 0,040 & 0,253 & 9,000 & 44,253 & 17,187 & 0,067 & 0,773 & 0,000 & 14,000 \\
\hline 72 & T07 & BA3 & 0,040 & 0,293 & 1,720 & 33,493 & 20,667 & 0,027 & 0,413 & 0,000 & 14,960 \\
\hline 73 & T08 & BA5 & 0,040 & 0,453 & 5,360 & 49,453 & 10,107 & 0,307 & 0,333 & 0,000 & 15,920 \\
\hline 74 & T09 & BA7 & 0,000 & 0,253 & 1,400 & 23,213 & 22,107 & 0,067 & 0,293 & 0,000 & 16,280 \\
\hline 75 & T010 & BA9 & 0,040 & 0,293 & 6,720 & 33,133 & 11,107 & 0,000 & 0,213 & 0,120 & 14,800 \\
\hline 76 & T011 & C01 & 0,040 & 0,293 & 0,920 & 30,493 & 32,227 & 0,107 & 0,773 & 0,000 & 35,200 \\
\hline 77 & T012 & $\mathrm{CO2}$ & 0,040 & 0,373 & 7,080 & 39,453 & 15,827 & 0,107 & 0,453 & 0,000 & 14,040 \\
\hline 78 & T013 & $\mathrm{CO3}$ & 0,040 & 0,333 & 2,200 & 29,973 & 23,827 & 0,067 & 0,493 & 0,000 & 23,440 \\
\hline 79 & T014 & $\mathrm{CO4}$ & 0,040 & 0,413 & 5,880 & 45,053 & 19,787 & 0,427 & 0,213 & 0,000 & 19,080 \\
\hline 80 & T015 & $\mathrm{C} 05$ & 0,040 & 0,373 & 1,320 & 34,373 & 17,187 & 0,667 & 0,213 & 0,000 & 21,320 \\
\hline
\end{tabular}

1 Identificação dos vegetais (AL: alface, BA: batata, BE: beterraba, CE: cenoura, RE: repolho, TO: tomate) São João del Rei e VI: Viçosa

${ }^{3}$ Valores referidos como iguais a zero não indicam, obrigatoriamente, ausência dos elementos analizados e, sim, que os teores não atingiram o limite de detecção do equipamento ICP-OES

Tabela 4. Teores totais de metais pesados avaliados nas amostras de olerícolas coletadas no CEASA-MG

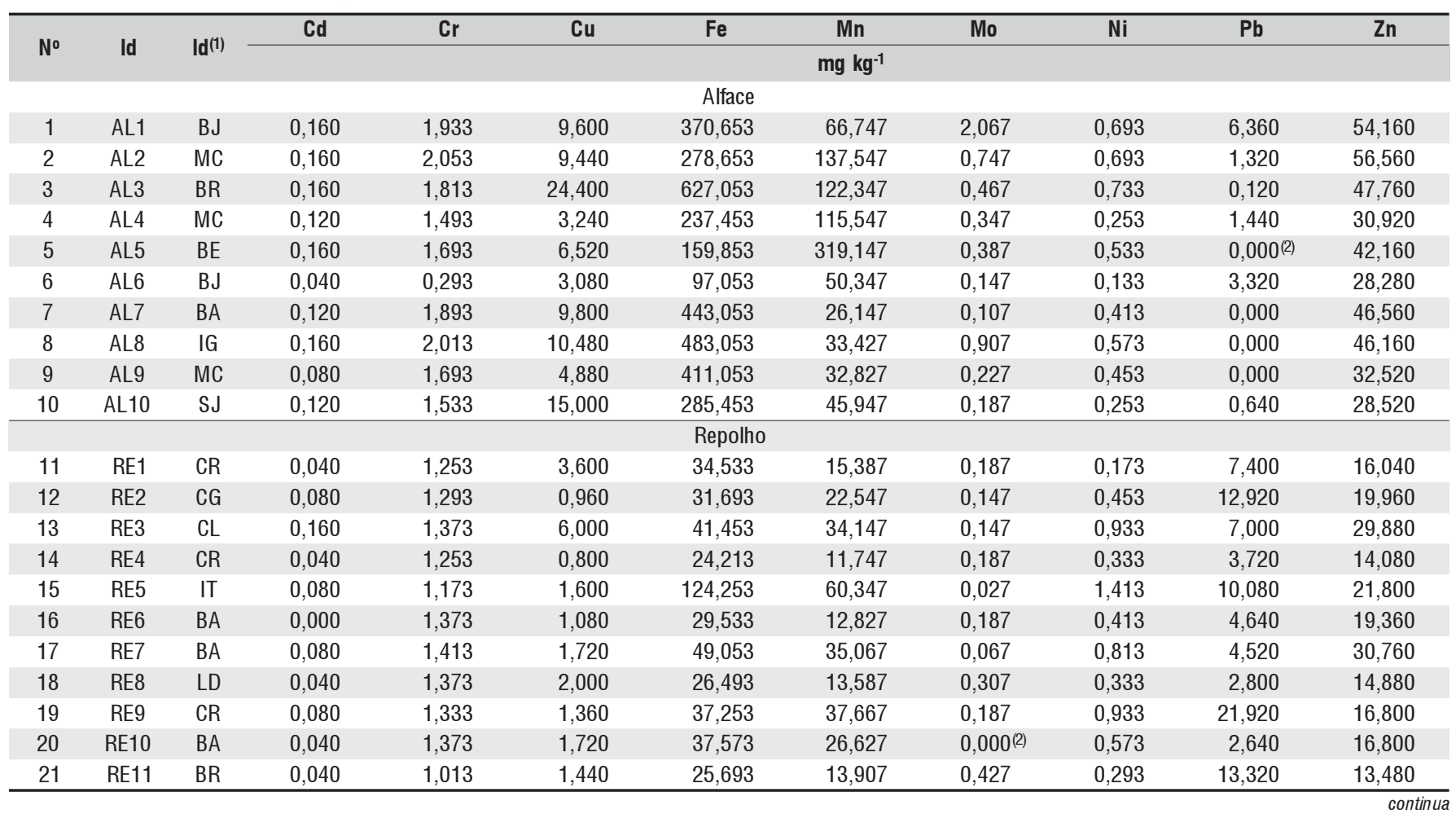


Tabela 4. (continuação)

\begin{tabular}{|c|c|c|c|c|c|c|c|c|c|c|c|}
\hline \multirow{2}{*}{ No } & \multirow{2}{*}{ Id } & \multirow{2}{*}{ Id (1) } & Cd & $\mathrm{Cr}$ & $\mathrm{Cu}$ & $\mathrm{Fe}$ & $M n$ & Mo & $\mathrm{Ni}$ & $\mathrm{Pb}$ & $\mathrm{Zn}$ \\
\hline & & & \multicolumn{9}{|c|}{$\mathrm{mg} \mathrm{kg}^{-1}$} \\
\hline 22 & RE12 & $\mathrm{CR}$ & 0,080 & 1,173 & 2,720 & 32,493 & 41,547 & 0,387 & 1,533 & 3,320 & 19,120 \\
\hline 23 & RE13 & $\mathrm{CR}$ & 0,040 & 1,253 & 3,000 & 31,133 & 21,507 & 0,027 & 1,133 & 6,840 & 16,800 \\
\hline 24 & RE14 & $\mathrm{BA}$ & 0,080 & 1,453 & 1,800 & 45,853 & 36,627 & 0,347 & 0,453 & 6,840 & 38,280 \\
\hline 25 & RE15 & LD & 0,040 & 1,333 & 1,320 & 27,693 & 17,787 & 0,147 & 0,493 & 3,520 & 17,360 \\
\hline 26 & RE16 & LD & 0,080 & 1,693 & 7,960 & 167,853 & 26,107 & 0,147 & 0,573 & 2,560 & 27,120 \\
\hline 27 & RE17 & SJ & 0,040 & 1,333 & 4,560 & 71,053 & 17,387 & 0,987 & 0,293 & 331,600 & 31,320 \\
\hline 28 & RE18 & $\mathrm{BA}$ & 0,040 & 1,373 & 2,160 & 53,453 & 57,547 & 0,107 & 1,093 & 6,760 & 51,360 \\
\hline 29 & RE19 & LD & 0,040 & 1,573 & 2,400 & 66,653 & 51,947 & 0,067 & 1,533 & 3,040 & 23,480 \\
\hline 30 & RE20 & LD & 0,040 & 1,253 & 2,040 & 41,453 & 23,787 & 0,027 & 0,413 & 4,520 & 21,640 \\
\hline \multicolumn{12}{|c|}{ Cenoura } \\
\hline 31 & CE1 & $S G$ & 0,040 & 1,053 & 4,720 & 29,773 & 9,867 & 0,000 & 0,253 & 20,840 & 19,720 \\
\hline 32 & CE2 & F0 & 0,040 & 1,213 & 3,160 & 32,813 & 10,307 & 0,000 & 0,173 & 0,000 & 12,760 \\
\hline 33 & CE3 & F0 & 0,120 & 1,213 & 3,000 & 43,853 & 10,507 & 0,067 & 0,213 & 0,000 & 19,320 \\
\hline 34 & CE4 & SJ & 0,080 & 1,573 & 3,000 & 49,853 & 13,107 & 0,067 & 0,373 & 0,000 & 21,520 \\
\hline 35 & CE5 & $S G$ & 0,040 & 1,333 & 2,040 & 53,853 & 5,787 & 0,000 & 0,213 & 0,000 & 18,440 \\
\hline 36 & CE6 & LD & 0,040 & 0,973 & 1,520 & 23,133 & 9,387 & 0,000 & 0,133 & 0,000 & 13,240 \\
\hline 37 & CE7 & $\mathrm{CR}$ & 0,040 & 1,293 & 2,800 & 155,053 & 8,627 & 0,107 & 0,333 & 2,760 & 12,960 \\
\hline 38 & CE8 & $S G$ & 0,040 & 1,373 & 7,080 & 23,973 & 5,307 & 0,027 & 0,253 & 0,000 & 30,000 \\
\hline 39 & CE9 & $\mathrm{SG}$ & 0,040 & 1,493 & 3,640 & 38,293 & 7,107 & 0,000 & 0,293 & 0,000 & 18,920 \\
\hline 40 & CE10 & LD & 0,040 & 1,333 & 3,200 & 45,853 & 5,867 & 0,027 & 0,173 & 0,000 & 12,680 \\
\hline 41 & CE11 & CG & 0,120 & 1,333 & 4,240 & 25,053 & 3,547 & 0,187 & 0,133 & 0,000 & 16,720 \\
\hline 42 & CE12 & $S G$ & 0,080 & 1,293 & 4,600 & 78,253 & 5,587 & 0,107 & 0,133 & 0,000 & 17,960 \\
\hline 43 & CE13 & $S G$ & 0,040 & 1,373 & 3,400 & 36,653 & 4,307 & 0,067 & 0,133 & 0,000 & 13,240 \\
\hline 44 & CE14 & $S G$ & 0,040 & 1,413 & 2,480 & 38,133 & 4,827 & 0,027 & 0,133 & 0,000 & 22,680 \\
\hline 45 & CE15 & $S G$ & 0,040 & 1,413 & 3,960 & 30,933 & 8,867 & 0,067 & 0,213 & 0,000 & 18,160 \\
\hline 46 & CE16 & LD & 0,160 & 1,333 & 2,680 & 19,613 & 8,227 & 0,000 & 0,213 & 33,600 & 11,960 \\
\hline 47 & CE17 & $S G$ & 0,080 & 1,453 & 8,080 & 78,253 & 6,907 & 0,067 & 0,133 & 0,000 & 22,880 \\
\hline 48 & CE18 & $\mathrm{CR}$ & 0,040 & 1,413 & 4,040 & 53,853 & 23,027 & 0,000 & 0,173 & 0,000 & 27,000 \\
\hline 49 & CE19 & LD & 0,080 & 1,333 & 6,240 & 33,613 & 6,867 & 0,027 & 0,253 & 96,400 & 14,240 \\
\hline 50 & CE20 & MD & 0,120 & 1,253 & 1,960 & 65,053 & 8,787 & 0,000 & 0,133 & 0,000 & 13,880 \\
\hline \multicolumn{12}{|c|}{ Beterraba } \\
\hline 51 & BE1 & $\mathrm{CR}$ & 0,080 & 1,693 & 2,920 & 33,493 & 85,947 & 0,027 & 0,453 & 0,000 & 16,240 \\
\hline 52 & BE2 & $\mathrm{PI}$ & 0,080 & 1,533 & 8,480 & 85,053 & 113,947 & 0,107 & 0,173 & 0,000 & 53,760 \\
\hline 53 & BE3 & SJ & 0,120 & 1,333 & 2,800 & 60,253 & 24,627 & 0,000 & 0,293 & 0,000 & 22,520 \\
\hline 54 & BE4 & CG & 0,120 & 1,253 & 4,560 & 48,253 & 36,027 & 0,067 & 0,173 & 44,000 & 22,560 \\
\hline 55 & BE5 & LD & 0,080 & 1,373 & 6,680 & 76,253 & 9,827 & 0,107 & 0,173 & 0,000 & 26,680 \\
\hline 56 & BE6 & LD & 0,080 & 1,373 & 9,520 & 45,053 & 29,507 & 0,000 & 0,133 & 0,000 & 68,160 \\
\hline 57 & BE7 & QU & 0,160 & 1,373 & 11,080 & 54,253 & 161,947 & 0,000 & 0,813 & 0,000 & 115,360 \\
\hline 58 & BE8 & LD & 0,040 & 1,373 & 6,360 & 35,613 & 33,467 & 0,067 & 0,173 & 0,000 & 26,120 \\
\hline 59 & BE9 & CG & 0,080 & 1,373 & 3,640 & 29,173 & 57,147 & 0,000 & 0,213 & 9,640 & 12,520 \\
\hline 60 & BE10 & LD & 0,040 & 1,493 & 6,000 & 40,253 & 16,427 & 0,147 & 0,213 & 0,000 & 28,640 \\
\hline 61 & BE11 & CS & 0,080 & 1,653 & 2,440 & 45,453 & 16,227 & 0,027 & 0,253 & 0,000 & 20,240 \\
\hline 62 & BE12 & $S G$ & 0,080 & 1,413 & 8,200 & 44,653 & 39,547 & 0,027 & 0,213 & 0,000 & 32,240 \\
\hline 63 & BE13 & $S G$ & 0,080 & 1,613 & 6,360 & 33,573 & 18,227 & 0,107 & 0,373 & 0,000 & 46,960 \\
\hline 64 & BE14 & LD & 0,080 & 1,293 & 8,120 & 59,853 & 54,747 & 0,027 & 0,253 & 0,000 & 43,360 \\
\hline 65 & BE15 & $S G$ & 0,040 & 1,373 & 4,680 & 37,773 & 10,067 & 0,187 & 0,093 & 0,000 & 22,200 \\
\hline 66 & BE16 & LD & 0,040 & 1,533 & 5,160 & 45,053 & 8,227 & 0,267 & 0,133 & 0,000 & 32,960 \\
\hline 67 & BE17 & SJ & 0,080 & 1,333 & 8,360 & 29,893 & 87,547 & 0,000 & 0,333 & 0,000 & 84,960 \\
\hline 68 & BE18 & SJ & 0,080 & 1,413 & 3,480 & 33,293 & 78,347 & 0,027 & 0,373 & 0,000 & 32,720 \\
\hline 69 & BE19 & SJ & 0,040 & 1,413 & 6,600 & 47,853 & 63,947 & 0,027 & 0,453 & 0,000 & 33,080 \\
\hline 70 & BE20 & SJ & 0,080 & 1,453 & 3,600 & 42,653 & 77,147 & 0,027 & 0,453 & 0,000 & 35,920 \\
\hline \multicolumn{12}{|c|}{ Batata } \\
\hline 71 & BA1 & $\mathrm{BR}$ & 0,040 & 1,493 & 4,800 & 28,093 & 9,187 & 0,000 & 0,093 & 2,240 & 14,320 \\
\hline 72 & BA2 & $\mathrm{BR}$ & 0,080 & 1,333 & 3,480 & 21,773 & 4,107 & 0,067 & 0,133 & 0,000 & 15,120 \\
\hline 73 & BA3 & $\mathrm{BM}$ & 0,040 & 1,373 & 3,000 & 18,333 & 8,547 & 0,107 & 0,253 & 0,000 & 10,040 \\
\hline 74 & BA4 & ES & 0,040 & 1,413 & 7,040 & 25,333 & 6,867 & 0,000 & 0,293 & 0,000 & 17,560 \\
\hline 75 & BA5 & BB & 0,080 & 1,493 & 4,080 & 26,253 & 7,187 & 0,067 & 0,253 & 0,000 & 14,240 \\
\hline 76 & BA6 & $\mathrm{BR}$ & 0,040 & 1,453 & 5,000 & 24,013 & 6,987 & 0,027 & 0,293 & 0,000 & 14,640 \\
\hline
\end{tabular}


Tabela 4. (continuação)

\begin{tabular}{|c|c|c|c|c|c|c|c|c|c|c|c|}
\hline \multirow{2}{*}{$\mathrm{N}^{0}$} & \multirow{2}{*}{ Id } & \multirow{2}{*}{ Id (1) } & Cd & $\mathrm{Cr}$ & $\mathrm{Cu}$ & $\mathrm{Fe}$ & $\mathrm{Mn}$ & Mo & $\mathrm{Ni}$ & $\mathrm{Pb}$ & $\mathrm{Zn}$ \\
\hline & & & \multicolumn{9}{|c|}{$\mathrm{mg} \mathrm{kg}^{-1}$} \\
\hline 77 & BA7 & $\mathrm{BR}$ & 0,040 & 1,533 & 6,320 & 27,093 & 6,187 & 0,027 & 0,133 & 0,000 & 16,920 \\
\hline 78 & BA8 & $\mathrm{TM}$ & 0,040 & 1,413 & 5,680 & 24,293 & 7,547 & 0,107 & 0,253 & 0,000 & 15,640 \\
\hline 79 & BA9 & $\mathrm{OB}$ & 0,040 & 1,533 & 1,920 & 16,893 & 7,427 & 0,107 & 0,173 & 0,000 & 12,000 \\
\hline 80 & BA10 & $\mathrm{NI}$ & 0,080 & 1,413 & 6,000 & 23,053 & 6,427 & 0,027 & 0,453 & 4,560 & 11,720 \\
\hline 81 & BA11 & $\mathrm{NI}$ & 0,040 & 1,373 & 2,240 & 26,093 & 4,027 & 0,107 & 0,133 & 0,000 & 12,160 \\
\hline 82 & BA12 & $\mathrm{NI}$ & 0,080 & 1,453 & 3,600 & 34,053 & 4,547 & 0,147 & 0,173 & 0,000 & 12,720 \\
\hline 83 & BA13 & AR & 0,040 & 1,413 & 3,280 & 27,693 & 4,107 & 0,067 & 0,133 & 0,000 & 11,480 \\
\hline 84 & BA14 & $A R$ & 0,000 & 1,373 & 2,800 & 25,173 & 4,387 & 0,027 & 0,053 & 0,000 & 10,720 \\
\hline 85 & BA15 & SJ & 0,120 & 1,453 & 3,040 & 27,413 & 4,347 & 0,027 & 0,333 & 1,960 & 8,880 \\
\hline 86 & BA16 & SA & 0,040 & 1,333 & 2,760 & 26,413 & 7,827 & 0,067 & 0,093 & 0,000 & 12,680 \\
\hline 87 & BA17 & $\mathrm{AR}$ & 0,080 & 1,333 & 6,160 & 21,773 & 5,347 & 0,267 & 0,413 & 0,000 & 15,040 \\
\hline 88 & BA18 & $\mathrm{AR}$ & 0,120 & 1,293 & 2,880 & 29,253 & 4,187 & 0,067 & 0,173 & 0,000 & 9,640 \\
\hline 89 & BA19 & $S G$ & 0,040 & 1,573 & 5,080 & 30,933 & 4,627 & 0,107 & 0,173 & 0,000 & 16,200 \\
\hline 90 & BA20 & SJ & 0,080 & 1,333 & 1,640 & 21,973 & 4,547 & 0,000 & 0,253 & 0,000 & 8,840 \\
\hline 91 & BA21 & $\mathrm{AR}$ & 0,040 & 1,373 & 4,480 & 32,093 & 4,787 & 0,187 & 0,093 & 0,000 & 15,440 \\
\hline 92 & BA22 & $S G$ & 0,040 & 1,453 & 6,280 & 30,253 & 4,907 & 0,027 & 0,213 & 6,680 & 13,200 \\
\hline 93 & BA23 & $\mathrm{AR}$ & 0,040 & 1,373 & 3,440 & 18,573 & 4,787 & 0,067 & 0,093 & 0,000 & 10,520 \\
\hline \multicolumn{12}{|c|}{ Tomate } \\
\hline 94 & T01 & PM & 0,080 & 1,573 & 5,040 & 50,653 & 20,667 & 0,000 & 0,293 & 0,000 & 14,000 \\
\hline 95 & T02 & $\mathrm{CR}$ & 0,120 & 1,333 & 6,240 & 34,053 & 18,347 & 0,000 & 0,413 & 0,000 & 14,800 \\
\hline 96 & T03 & $\mathrm{CR}$ & 0,040 & 1,413 & 5,440 & 36,373 & 21,307 & 0,027 & 0,373 & 0,000 & 16,120 \\
\hline 97 & T04 & $\mathrm{CR}$ & 0,080 & 1,453 & 9,960 & 41,453 & 14,387 & 0,107 & 0,253 & 0,000 & 23,880 \\
\hline 98 & T05 & $\mathrm{CR}$ & 0,040 & 1,493 & 6,880 & 69,853 & 22,547 & 0,147 & 0,293 & 0,000 & 16,280 \\
\hline 99 & T06 & $\mathrm{CM}$ & 0,080 & 1,453 & 9,160 & 28,733 & 12,907 & 0,107 & 0,373 & 0,000 & 15,120 \\
\hline 100 & T07 & $\mathrm{CM}$ & 0,040 & 1,853 & 8,680 & 38,533 & 14,427 & 0,507 & 0,293 & 0,000 & 18,240 \\
\hline 101 & T08 & PM & 0,080 & 1,453 & 5,080 & 37,293 & 17,427 & 0,547 & 0,093 & 0,000 & 11,640 \\
\hline 102 & T09 & $\mathrm{SZ}$ & 0,040 & 1,493 & 11,680 & 43,853 & 38,067 & 0,267 & 0,493 & 0,000 & 22,120 \\
\hline 103 & T010 & LD & 0,120 & 1,333 & 8,560 & 37,693 & 20,267 & 0,027 & 0,293 & 0,000 & 13,760 \\
\hline 104 & T011 & BA & 0,040 & 1,773 & 5,400 & 31,733 & 14,867 & 0,067 & 0,373 & 0,000 & 12,720 \\
\hline 105 & T012 & $\mathrm{BA}$ & 0,080 & 1,493 & 3,800 & 27,733 & 12,507 & 0,000 & 0,293 & 0,000 & 14,160 \\
\hline 106 & T013 & $\mathrm{CR}$ & 0,040 & 1,373 & 5,680 & 35,253 & 13,987 & 0,507 & 0,173 & 0,000 & 16,040 \\
\hline 107 & T014 & SM & 0,080 & 1,533 & 5,600 & 47,853 & 16,627 & 0,107 & 0,213 & 0,000 & 20,520 \\
\hline 108 & T015 & $\mathrm{CA}$ & 0,080 & 1,453 & 6,520 & 38,853 & 16,867 & 0,027 & 0,173 & 0,000 & 18,920 \\
\hline 109 & T016 & PM & 0,080 & 1,533 & 8,880 & 38,333 & 10,667 & 0,427 & 0,533 & 0,000 & 17,480 \\
\hline 110 & T017 & BA & 0,080 & 1,453 & 8,920 & 48,653 & 12,587 & 0,307 & 0,293 & 0,000 & 19,840 \\
\hline 111 & T018 & $\mathrm{CR}$ & 0,040 & 1,533 & 5,920 & 53,453 & 21,427 & 0,027 & 0,293 & 0,000 & 19,040 \\
\hline 112 & T019 & LD & 0,040 & 1,413 & 7,080 & 42,253 & 13,907 & 0,107 & 0,333 & 0,000 & 16,600 \\
\hline 113 & T020 & CT & 0,040 & 1,373 & 11,760 & 42,253 & 36,507 & 0,027 & 0,413 & 0,000 & 17,480 \\
\hline 114 & T021 & SJ & 0,040 & 1,213 & 5,160 & 40,253 & 38,027 & 0,347 & 0,253 & 0,000 & 14,120 \\
\hline
\end{tabular}

${ }^{1}$ Município de origem do vegetal: AR: Araxá; BA: Barbacena; BE: Betim; BJ: Bom Jardim; BR: Bom Repouso; BM: Borda da Mata; BR: Brumadinho; BB: Bueno Brandão; CR: Carandaí; CT: Caratinga; CM: Carmópolis de Minas; CG: Casagrande, CL: Conselheiro Lafaiete; CR: Crucilândia; ES: Estiva; F0: Formiga; IG: Igarapé; IT: Itatiaiçu; LD: Lagoa Dourada; MD: Madre de Deus; MC: Mario Campos; NI: município não identificado; OB: Ouro Branco; PM: Pará de Minas; PI: Pedro do Indaiá; QU: Queluzito; SJ: Santa Juliana; SG: São Gotardo; SJ: São João del Rei; SM: São João Manhuaçu; SA: Senador Amaral; SZ: Serra Azul; TM: Tocos do Mugi

2 Valores referidos como iguais a zero não indicam, obrigatoriamente, ausência dos elementos analisados e, sim, que os teores não atingiram o limite de detecção do equipamento ICP-OES

Tabela 5. Teores totais de metais pesados avaliados em amostras de água utilizadas para irrigação de cultivos de olerícolas no Estado de Minas Gerais

\begin{tabular}{|c|c|c|c|c|c|c|c|c|c|c|c|}
\hline \multirow{2}{*}{$\mathrm{N}^{0}$} & \multirow{2}{*}{ Id $^{(1)}$} & \multirow{2}{*}{ Água(2) } & Cd & $\mathrm{Cr}$ & $\mathrm{Cu}$ & $\mathrm{Fe}$ & Mn & Mo & $\mathrm{Ni}$ & $\mathbf{P b}$ & $\mathrm{Zn}$ \\
\hline & & & \multicolumn{9}{|c|}{$\mu \mathrm{g} \mathrm{mL}^{-1}$} \\
\hline 1 & Vl1 & represa & $0,000^{(3)}$ & 0,043 & 0,010 & 1,108 & 0,123 & 0,001 & 0,021 & 0,000 & 0,051 \\
\hline 2 & $\mathrm{VI} 2$ & poço & 0,000 & 0,000 & 0,000 & 0,082 & 0,010 & 0,000 & 0,000 & 0,000 & 0,015 \\
\hline 3 & $\mathrm{Vl} 3 \mathrm{a}$ & poço & 0,000 & 0,010 & 0,007 & 0,678 & 0,027 & 0,000 & 0,005 & 0,000 & 0,018 \\
\hline 4 & Vl3b & córrego & 0,000 & 0,001 & 0,003 & 0,200 & 0,003 & 0,000 & 0,003 & 0,000 & 0,014 \\
\hline 5 & VI4 & $\left({ }^{*}\right)^{(4)}$ & 0,000 & 0,000 & 0,000 & 0,018 & 0,000 & 0,000 & 0,004 & 0,000 & 0,012 \\
\hline 6 & VI5 & $\left({ }^{*}\right)$ & 0,000 & 0,029 & 0,006 & 0,123 & 0,002 & 0,000 & 0,006 & 0,000 & 0,010 \\
\hline 8 & MC2 & córrego & 0,000 & 0,026 & 0,000 & 1,018 & 0,190 & 0,000 & 0,006 & 0,000 & 0,002 \\
\hline 9 & MC3 & mina & 0,000 & 0,005 & 0,002 & 0,130 & 0,011 & 0,001 & 0,002 & 0,000 & 0,003 \\
\hline 10 & MC4 & córrego & 0,000 & 0,000 & 0,000 & 0,720 & 0,156 & 0,000 & 0,005 & 0,000 & 0,018 \\
\hline
\end{tabular}


Tabela 5. (continuação)

\begin{tabular}{|c|c|c|c|c|c|c|c|c|c|c|c|}
\hline \multirow{2}{*}{ No } & \multirow{2}{*}{ Id(1) } & \multirow{2}{*}{ Água(2) } & Cd & $\mathrm{Cr}$ & $\mathrm{Cu}$ & $\mathrm{Fe}$ & $\mathrm{Mn}$ & Mo & $\mathrm{Ni}$ & $\mathrm{Pb}$ & $\mathrm{Zn}$ \\
\hline & & & \multicolumn{9}{|c|}{$\mu \mathrm{g} \mathrm{mL}^{-1}$} \\
\hline 11 & MC5 & córrego & 0,000 & 0,000 & 0,000 & 0,300 & 0,183 & 0,000 & 0,003 & 0,000 & 0,003 \\
\hline 12 & JF1 & córrego & 0,000 & 0,006 & 0,004 & 1,118 & 0,060 & 0,000 & 0,000 & 0,000 & 0,004 \\
\hline 13 & JF2 & córrego & 0,000 & 0,000 & 0,000 & 0,754 & 0,054 & 0,000 & 0,000 & 0,000 & 0,001 \\
\hline 14 & JF3 & $\left({ }^{\star}\right)$ & 0,000 & 0,000 & 0,000 & 2,248 & 0,050 & 0,000 & 0,000 & 0,000 & 0,040 \\
\hline 15 & JF4 & nascente & 0,000 & 0,004 & 0,001 & 0,813 & 0,029 & 0,000 & 0,001 & 0,000 & 0,000 \\
\hline 16 & JF5 & açude & 0,000 & 0,001 & 0,000 & 3,768 & 0,525 & 0,000 & 0,001 & 0,000 & 0,001 \\
\hline 17 & SG1 & açude & 0,000 & 0,000 & 0,000 & 0,299 & 0,020 & 0,000 & 0,003 & 0,000 & 0,062 \\
\hline 18 & BM1 & córrego & 0,000 & 0,007 & 0,005 & 8,338 & 0,572 & 0,000 & 0,000 & 0,000 & 0,007 \\
\hline 19 & $\mathrm{BM}^{*}$ & captação & 0,000 & 0,010 & 0,000 & 3,628 & 0,171 & 0,000 & 0,004 & 0,000 & 0,002 \\
\hline 20 & $\mathrm{BM}^{*}$ & jusante & 0,001 & 0,001 & 0,000 & 2,608 & 0,124 & 0,000 & 0,000 & 0,000 & 0,000 \\
\hline 21 & BR1 & córrego & 0,000 & 0,004 & 0,003 & 1,518 & 0,033 & 0,000 & 0,000 & 0,000 & 0,003 \\
\hline 22 & BR2 & córrego & 0,000 & 0,000 & 0,000 & 1,838 & 0,075 & 0,000 & 0,000 & 0,000 & 0,001 \\
\hline 23 & BR3 & córrego & 0,000 & 0,000 & 0,000 & 2,548 & 0,064 & 0,000 & 0,000 & 0,000 & 0,007 \\
\hline 24 & $\mathrm{CA} 1+\mathrm{CA} 2$ & rio & 0,000 & 0,065 & 0,013 & 1,648 & 0,053 & 0,000 & 0,011 & 0,000 & 0,007 \\
\hline 25 & CA3 & nascente & 0,000 & 0,014 & 0,002 & 0,648 & 0,064 & 0,000 & 0,001 & 0,000 & 0,006 \\
\hline 26 & CA4 & represa & 0,000 & 0,000 & 0,000 & 0,755 & 0,011 & 0,000 & 0,000 & 0,000 & 0,006 \\
\hline 27 & CA5 & represa & 0,000 & 0,012 & 0,005 & 1,618 & 0,067 & 0,000 & 0,003 & 0,000 & 0,009 \\
\hline 28 & CA6 & córrego & 0,000 & 0,005 & 0,001 & 2,148 & 0,050 & 0,001 & 0,006 & 0,000 & 0,003 \\
\hline 29 & CA7 & represa & 0,000 & 0,001 & 0,000 & 1,288 & 0,021 & 0,000 & 0,002 & 0,000 & 0,001 \\
\hline 30 & CA8 & córrego & 0,000 & 0,003 & 0,002 & 1,778 & 0,046 & 0,000 & 0,001 & 0,000 & 0,027 \\
\hline 31 & $\mathrm{CA} 9+\mathrm{CA} 10$ & córrego & 0,000 & 0,007 & 0,003 & 2,048 & 0,046 & 0,000 & 0,005 & 0,000 & 0,000 \\
\hline 32 & CA11 & represa & 0,000 & 0,000 & 0,000 & 1,348 & 0,010 & 0,000 & 0,000 & 0,000 & 0,000 \\
\hline 33 & CA12 & represa & 0,000 & 0,002 & 0,067 & 2,438 & 0,018 & 0,000 & 0,002 & 0,000 & 0,039 \\
\hline 34 & CA13 & córrego & 0,000 & 0,007 & 0,004 & 2,098 & 0,058 & 0,000 & 0,002 & 0,000 & 0,003 \\
\hline 35 & CA14 & córrego & 0,000 & 0,000 & 0,000 & 2,098 & 0,022 & 0,000 & 0,004 & 0,000 & 0,001 \\
\hline 36 & CA15 & nascente & 0,000 & 0,006 & 0,000 & 1,268 & 0,007 & 0,000 & 0,002 & 0,000 & 0,001 \\
\hline 37 & CA16 & nascente & 0,000 & 0,011 & 0,007 & 7,658 & 0,098 & 0,000 & 0,003 & 0,000 & 0,010 \\
\hline 38 & BA1 & represa & 0,000 & 0,000 & 0,000 & 0,998 & 0,020 & 0,000 & 0,008 & 0,000 & 0,001 \\
\hline 39 & BA2 & nascente & 0,000 & 0,000 & 0,000 & 1,738 & 0,174 & 0,000 & 0,005 & 0,000 & 0,008 \\
\hline 40 & BA3 & córrego & 0,000 & 0,002 & 0,001 & 2,768 & 0,058 & 0,000 & 0,001 & 0,000 & 0,002 \\
\hline 41 & BA4 & Rio das Mortes & 0,000 & 0,000 & 0,046 & 2,978 & 0,132 & 0,000 & 0,003 & 0,000 & 0,001 \\
\hline 42 & $\mathrm{BA} 5+\mathrm{BA} 8$ & córrego & 0,000 & 0,000 & 0,000 & 1,378 & 0,039 & 0,000 & 0,004 & 0,000 & 0,002 \\
\hline 43 & BA6 & nascente & 0,000 & 0,000 & 0,000 & 0,968 & 0,058 & 0,000 & 0,000 & 0,000 & 0,000 \\
\hline 44 & $\mathrm{BA} 7+\mathrm{BA} 10$ & $\left(^{\star}\right)$ & 0,000 & 0,000 & 0,000 & 0,978 & 0,029 & 0,000 & 0,001 & 0,000 & 0,000 \\
\hline 45 & BA9 & Rio das Mortes & 0,000 & 0,000 & 0,000 & 0,928 & 0,034 & 0,000 & 0,001 & 0,000 & 0,000 \\
\hline 46 & LD1+LD2 & córrego & 0,000 & 0,297 & 0,005 & 3,938 & 0,071 & 0,000 & 0,060 & 0,000 & 0,005 \\
\hline 47 & LD3+LD4 & corrego & 0,000 & 0,010 & 0,001 & 1,488 & 0,157 & 0,000 & 0,001 & 0,000 & 0,006 \\
\hline 48 & LD5 & córrego & 0,000 & 0,000 & 0,000 & 2,228 & 0,296 & 0,000 & 0,003 & 0,000 & 0,000 \\
\hline 49 & LD6 & rio & 0,000 & 0,006 & 0,001 & 1,668 & 0,072 & 0,000 & 0,002 & 0,000 & 0,005 \\
\hline 50 & LD7+LD9 & córrego & 0,000 & 0,000 & 0,000 & 1,058 & 0,110 & 0,001 & 0,000 & 0,000 & 0,029 \\
\hline 51 & LD8 & nascente & 0,000 & 0,003 & 0,003 & 4,088 & 0,178 & 0,000 & 0,014 & 0,000 & 0,004 \\
\hline 52 & $\mathrm{C} 01$ & córrego & 0,000 & 0,007 & 0,002 & 9,188 & 0,291 & 0,000 & 0,001 & 0,000 & 0,000 \\
\hline 53 & $\mathrm{CO2}$ & córrego & 0,000 & 0,000 & 0,000 & 3,038 & 0,070 & 0,000 & 0,003 & 0,000 & 0,000 \\
\hline 54 & $\mathrm{CO} 3$ & córrego & 0,000 & 0,003 & 0,003 & 1,388 & 0,124 & 0,002 & 0,001 & 0,000 & 0,013 \\
\hline 55 & $\mathrm{CO} 4$ & nascente & 0,000 & 0,000 & 0,000 & 3,388 & 0,341 & 0,001 & 0,004 & 0,000 & 0,006 \\
\hline 56 & $\mathrm{CO5}$ & córrego & 0,001 & 0,000 & 0,000 & 14,228 & 0,447 & 0,002 & 0,006 & 0,000 & 0,001 \\
\hline 57 & $\mathrm{CO}^{*}$ & captação & 0,000 & 0,000 & 0,000 & 2,378 & 0,211 & 0,000 & 0,001 & 0,000 & 0,005 \\
\hline 58 & SJ1 & Rio Carandaí & 0,000 & 0,000 & 0,007 & 1,298 & 0,073 & 0,000 & 0,001 & 0,000 & 0,129 \\
\hline 59 & SJ2 & Rio das Mortes & $n d^{(5)}$ & nd & nd & nd & nd & nd & nd & nd & $\mathrm{Nd}$ \\
\hline 60 & SJ3 & córrego & 0,000 & 0,000 & 0,000 & 1,078 & 0,078 & 0,000 & 0,002 & 0,000 & 0,000 \\
\hline 61 & SJ4 & represa & 0,000 & 0,000 & 0,000 & 1,178 & 0,018 & 0,000 & 0,000 & 0,000 & 0,011 \\
\hline 62 & SJ5 & córrego & 0,000 & 0,000 & 0,000 & 2,098 & 0,027 & 0,000 & 0,005 & 0,000 & 0,004 \\
\hline
\end{tabular}

${ }^{1}$ Município de coleta: BA: Barbacena, BR: Bom Repouso, BM: Borda da Mata, CA: Carandaí, C0: Coimbra, JF: Juiz de Fora, LD:Lagoa Dourada, MC: Mário Campos, SG: São Gotardo, SJ: São João del Rei e Vl: Viçosa

2 Origem da amostra de água coletada

3 Valores referidos como iguais a zero não indicam, obrigatoriamente, ausência dos elementos analisados e, sim, que os teores não atingiram o limite de detecção do equipamento ICP-OES

${ }^{4}$ Amostras recolhidas junto ao sistema de irrigação sem identificação precisa de sua origem $\left(^{*}\right)$

${ }^{5} \mathrm{Nd}$ : amostra perdida durante a análise

$\mathrm{BM}^{*} \mathrm{e} \mathrm{CO}^{*}$ - Amostras extras próximas à captação de água das cidades ou à sua jusante 
geográfica abrangida e pela possibilidade de permitir identificar áreas potencialmente merecedoras de novos e mais aprofundados estudos. A análise pontual de amostras de água no tempo e no espaço permite a obtenção de resultados que podem não ser reproduzíveis ao longo do tempo, tendo em vista a variabilidade decorrente da própria dinâmica do corpo líquido, sendo apenas um retrato instantâneo do momento da amostragem. Mesmo com essa limitação, os dados obtidos são válidos e merecem consideração no intuito de se identificar tendências e comportamentos gerais, revestindo-se de grande significância para o estudo das águas mineiras.

Como é comum em estudos dessa natureza, os teores obtidos foram comparados com a Resolução 357/05 do Conselho Nacional do Meio Ambiente (CONAMA, 2005) que estabelece os teores máximos para substâncias potencialmente prejudiciais. Foram considerados os limites estabelecidos para as águas doces das Classes 1 e 2.

O Cd foi identificado em apenas uma amostra de um córrego do município de Coimbra (CO5), mostrando teor coincidente com o limite máximo $\left(0,001 \mathrm{mg} \mathrm{L}^{-1}\right)$ permitido pela Resolução 357/05. Para o Cr, três amostras superaram o limite $\left(0,05 \mathrm{mg} \mathrm{L}^{-1}\right)$, sendo que duas de forma pouco expressiva (MC1 e CA1+CA2) e uma terceira em maior intensidade, no município, de Lagoa Dourada (LD1+LD2).

No caso do $\mathrm{Cu}$ e Fe, cabe a ressalva de que os limites estabelecidos na Resolução 357/05 se referem à forma dissolvida. No presente estudo determinou-se o teor total, assim entendido como o somatório da fração solúvel e insolúvel, esta última associada às partículas presentes em suspensão na água. Neste sentido, torna-se difícil uma avaliação mais conclusiva acerca da qualidade das cinco amostras em que o limite de $\mathrm{Cu}$ foi superado. Considerando-se a resolução anterior (CONAMA, 1986) que vigorava na época da execução do presente trabalho e definia um limite para o teor total de $0,02 \mathrm{mg} \mathrm{L}^{-1}$, conclui-se que apenas duas amostras (CA12 e BA4) superariam o valor estabelecido. No caso do $\mathrm{Fe}$, a maioria das amostras apresentou teores superiores ao permitido na forma dissolvida $\left(0,3 \mathrm{mg} \mathrm{L}^{-1}\right)$. Ainda que não se tenha dados específicos das formas solúveis, os valores baixos de Fe total encontrados não devem representar maiores preocupações pois, seguramente, devem ser associados às partículas em suspensão, em especial às partículas de solo que são carregadas pelos rios e possuem, em sua constituição, minerais com elevado teor de Fe; raciocínio semelhante vale para o Mn, também expressivo na constituição química de minerais de solo.

Embora não seja contemplado na Resolução 357/05, o Mo foi identificado em sete das amostras analisadas; já os elementos $\mathrm{Ni}$ e Zn o foram em 48 amostras. No caso do Zn, em nenhuma das amostras se verificou teores acima do limite $\left(0,18 \mathrm{mg} \mathrm{L}^{-1}\right)$; entretanto, para o $\mathrm{Ni}$, uma amostra proveniente de Lagoa Dourada (LD1+LD2) exibiu teores mais que duas vezes superiores ao permitido $\left(0,025 \mathrm{mg} \mathrm{L}^{-1}\right)$.

\section{CONCLUSÕES}

1. As amostras de solo, plantas e águas coletadas no Es- tado de Minas Gerais associadas aos cultivos olerícolas apresentavam-se, de forma geral, livres de contaminação significativa de metais pesados.

2. Em algumas amostras específicas de solo com teores totais mais expressivos de metais pesados, a baixa disponibilidade desses elementos sugere que tal verificação não constitui problema de maior magnitude.

3. Algumas amostras de água apresentam teores preocupantes de metais pesados, indicando a necessidade de um programa de monitoramento dos pontos de coleta para identificação da possível fonte de contaminação.

\section{LITERATURA CITADA}

Abreu, C. A.; Abreu, M. F.; Andrade, J. C. Determinação de cobre, ferro, manganês, zinco, cádmio, cromo, níquel e chumbo em solos usando a solução de DTPA em pH 7,3. In: van Raij, B.; Andrade, J.C.; Cantarella, H.; Quaggio, J.A. (ed.). Análise química para avaliação da fertilidade de solos tropicais. Campinas: IAC, 2001. p.240-250.

Alloway, B. J. Heavy metals in soils. 2.ed. London: Blackie Academic \& Profesional, 1997. 368p.

Alvarez, V. H.; Novais, R. F.; Barros, N. F.; Cantarutti, R. B.; Lopes, A. S. Interpretação dos resultados das análises de solos. In: Ribeiro, A. C.; Guimarães, P. T. G.; Alvarez, V. H. (ed.). Recomendações para o uso de corretivos e fertilizantes em Minas Gerais - 5a Aproximação. Viçosa: CFSEMG, 1999. p.25-32.

ANVISA - Agência Nacional de Vigilância Sanitária. Portaria n.685. Publicada em 27/08/1998. Ministério da Saúde, Brasília. http://www.anvisa.gov.br/legis/portarias/ 685_98.htm. 15 Set. 2004.

Baker, D. E.; Amacher, M. C. Nickel, Copper, Zinc and Cadmium. In: Page, A. L.; Miller, R. H.; Keeney, D. R. (ed.). Methods of soil analysis, Part 2, Chemical and microbiological properties, 2.ed., Madison: ASA, SSSA, p.323-336. 1982.

Campos, M. L.; Pierangeli, M. A. P.; Guilherme, L. R. G.; Marques, J. J.; Curi, N. Baseline concentration of heavy metals in Brazilian Latosols. Communications in Soil Science and Plant Analysis, Athens, v.34, n.3-4, p.547-557, 2003

CETESB - Companhia de Tecnologia de Saneamento Ambiental. Decisão da Diretoria No 195/2005, de 23/11/2005. 2005. São Paulo: CETESB. http//www.cetesb.sp.gov.br/Solo/relatorios/ tabela_valores_2005.pdf. 6 Abr. 2005.

CETESB - Companhia de Tecnologia de Saneamento Ambiental. Rede de monitoramento de qualidade das águas interiores do Estado de São Paulo. Relatórios. São Paulo: CETESB, 2006. http//www.cetesb.sp.gov.br/Agua/rios/relatorios.asp. 10 Abr. 2006.

CONAMA - Conselho Nacional de Meio Ambiente. Resolução n. 20/1986. Publicada em 30/07/1986. Ministério do Meio Ambiente, Brasília. http://www.mma.gov.br/conama/res/res86/ res2086.html. 08 Ago. 2004.

CONAMA - Conselho Nacional de Meio Ambiente. Resolução n. 357/2005. Publicada em 17/03/2005. Ministério do Meio Ambiente, Brasília. http://www.mma.gov.br/conama/res/res05/ res35705.pdf. 13 Abr. 2006. 
Costa, A. C. M. ; Anjos, M. J.; Lopes, R. T.; Pérez, C. A.; Castro, C. R. F. Multi-element analysis of sea water from Sepetiba Bay, Brazil, by total reflection X-ray fluorescence spectrometry using synchrotron radiation. X-Ray Spectrometry, West Sussex, Inglaterra, v.34, n.3, p.183-188, 2005.

Costa, C. A.; Casali, V. W. D.; Loures, E. G.; Cecon, P. R.; Jordão, C. P. Teor de zinco, cobre e cádmio em cenoura em função de doses crescentes de composto de lixo urbano. Horticultura Brasileira, Brasília, v.15, n.1, p.10-14, 1997.

Costa, C. A.; Casali, V. W. D.; Ruiz, H. A.; Jordão, C. P.; Cecon, P. R. Teor de metais pesados e produção de alface adubada com composto de lixo urbano. Horticultura Brasileira, Brasília, v.19, p.10-16, 2001.

Deffelipo, B. V.; Ribeiro, A. C. Análise química do solo: Metodologia. Viçosa: UFV, 1996. 17p. Boletim, 29

Duarte, R. G. S.; Pasqual, A. Avaliação do cádmio (Cd), chumbo $(\mathrm{Pb})$, níquel $(\mathrm{Ni})$ e zinco $(\mathrm{Zn})$ em solos, plantas e cabelos humanos. Energia na Agricultura, Botucatu, v.15, n.1, p.46-58, 2000.

EMBRAPA - Empresa Brasileira de Pesquisa Agropecuária. Manual de métodos de análise de solo. Rio de Janeiro: CNPS, 1997. 212p.

Fadigas, F. S.; Amaral Sobrinho, N. M. B.; Mazur, N.; Anjos, L. H. C.; Freixo, A. A. Concentrações naturais de metais pesados em algumas classes de solos brasileiros. Bragantia, Campinas, v.61, n.2, p.151-159, 2002.

Fontes, M. P. F.; Gomes, P. C. Simultaneous competitive adsorption of heavy metals by the mineral matrix of tropical soils. Applied Geochemistry, Oxford, v.18, n.6, p.795-804, 2003.
Gomes, P. C.; Fontes, M. P. F.; Silva, A. G.; Mendonça, E. S.; Netto, A. R. Selectivity sequence and competitive adsorption of heavy metals by Brazilian soils. Soil Science Society of American Journal, Madison, v.65, p.1115-1121, 2001.

Kabata-Pendias, A.; Pendias, H. Trace elements in soils and plants. Flórida: Boca Raton, 1992. 365p.

Mantovani, J. R.; Ferreira, M. E.; Cruz, M. C. P.; Chiba, M. K.; Braz L. T. Calagem e adubação com vermicomposto de lixo urbano na produção e nos teores de metais pesados em alface. Horticultura Brasileira, Brasília, v.21, n.3, p.494500, 2003.

Marques, J. J.; Schulze, D. G.; Curi, N.; Mertzman, S. A. Trace element geochemistry in Brazilian Cerrado soils. Geoderma, Amsterdam, v.121, n.1-2, p.31-43, 2004.

NEPA - Núcleo de Estudos e Pesquisas em Alimentação. Tabela brasileira de composição de alimentos. Campinas: NEPA-UNICAMP, 2004. 42p. http://dtr2004.saude.gov.br/nutricao/documentos/tab_bras_de_comp_de_alim_doc.pdf. 11 Abr. 2006.

Ramalho, J. F. G. P.; Amaral Sobrinho, N. M. B.; Velloso, A. C. X. Contaminação da microbacia de Caetés com metais pesados pelo uso de agroquímicos. Pesquisa Agropecuária Brasileira, Brasília, v.35, n.7, p.1289-1303, 2000.

Rietzler, A. C.; Fonseca, A. L.; Lopes, G. P. Metais pesados em tributários da represa da Pampulha, Minas Gerais. Brazilian Journal of Biology, São Carlos, v.61, n.3, p.363-370, 2001.

Ruiz, H. A. Métodos de análises físicas do solo. Viçosa: DPS, UFV, 2004. 22p.

Teixeira, S. T.; Melo, W. J.; Silva, E. T. Metais pesados em solo degradado tratado com lodo de estação de tratamento de água. Scientia Agricola, Piracicaba, v.62, n.5, p.498-501, 2005. 